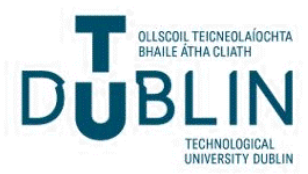

Technological University Dublin ARROW@TU Dublin

2022-2

\section{Using PHREEQC to model cement hydration}

Niall Holmes Dr.

Technological University Dublin, niall.holmes@tudublin.ie

Mark Tyrer

Coventry University

Roger P. West Prof

Trinity College Dublin, Ireland, rwest@tcd.ie

See next page for additional authors

Follow this and additional works at: https://arrow.tudublin.ie/engschcivart

Part of the Civil and Environmental Engineering Commons

\section{Recommended Citation}

Niall Holmes, Mark Tyrer, Roger West, Aaron Lowe, Denis Kelliher, Using PHREEQC to model cement hydration, Construction and Building Materials, Volume 319, 2022, 126129, ISSN 0950-0618, DOI: 10.1016/j.conbuildmat.2021.126129.

This Article is brought to you for free and open access by the School of Civil and Structural Engineering at ARROW@TU Dublin. It has been accepted for inclusion in Articles by an authorized administrator of ARROW@TU Dublin. For more information, please contact arrow.admin@tudublin.ie, aisling.coyne@tudublin.ie, gerard.connolly@tudublin.ie.

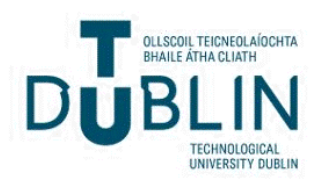




\section{Authors}

Niall Holmes Dr., Mark Tyrer, Roger P. West Prof, Aaron Lowe, and Denis Kelliher

This article is available at ARROW@TU Dublin: https://arrow.tudublin.ie/engschcivart/128 


\title{
Using PHREEQC to model cement hydration
}

\author{
Niall Holmes ${ }^{\mathrm{a}, \mathrm{b},{ }^{*}, \text { Mark Tyrer }^{\mathrm{a}, \mathrm{b}} \text {, Roger } \text { West }^{\mathrm{c}} \text {, Aaron Lowe }}{ }^{\mathrm{a}}$, Denis Kelliher ${ }^{\mathrm{d}}$ \\ ${ }^{a}$ School of Civil \& Structural Engineering, Technological University Dublin, Dublin 1, Ireland \\ ${ }^{\mathrm{b}}$ Institute of Advanced Study, Collegium Basilea, Basel, Switzerland \\ ${ }^{c}$ Department of Civil, Structural and Environmental Engineering, University of Dublin, Trinity College, Dublin 2, Ireland \\ ${ }^{\mathrm{d}}$ School of Civil, Structural and Environmental Engineering, University College Cork, Cork, Ireland
}

\section{A R T I C L E I N F O}

\section{Keywords:}

Cement

Hydration

Thermodynamics

PHREEQC

\begin{abstract}
A B S T R A C T
This paper presents the steps involved in undertaking an analysis of hydrating cements with different levels of limestone powder using the PHREEQC geochemical software with the Notepad++ editor. The analysis begins with determining which solid phases are thermodynamically predicted to precipitate and form using the oxide compositions of commercial CEM I and CEM II/A-L cements. When the phases are known, PHREEQC is programmed to provide predictions of the phase dissolution and phase assemblage over time (here, 1000 days of hydration) as well as the pore solution chemistry.

Thermodynamics has been successfully applied to the field of cement hydration to predict phase assemblages and pore solution changes. With an appropriate cement-based thermodynamic database, PHREEQC has the potential to be a very powerful tool in the ongoing development of sustainable cements into the future. The paper also discusses the ongoing work to couple PHREEQC with the HYDCEM model to provide users with an all-in-one platform to undertake a complete simulation of cement hydration.
\end{abstract}

\section{Introduction}

Thermodynamic modelling of cement hydration is a powerful technique to aid in understanding the equilibrium between phase assemblages, their pore solutions and the influence of temperature and chemical compositions upon them. Thermodynamic modelling, particularly in the interpretation of results, requires an understanding of which solids may be expected to dissolve or precipitate as reactions proceed to reach thermodynamic equilibrium. As the production of cements moves towards using more sustainable methods and materials, accurate predictions of hydrated phase assemblages will become increasingly important. Much research has been undertaken to predict phase assemblages using thermodynamic models using oxide proportions, water to cement (w/c) ratios and curing temperatures. An increasingly popular choice of thermodynamic analysis for cement hydration modelling is GEMS [1], which employs the Gibbs free energy minimization approach and uses the CEMDATA thermodynamic database [2] for cementitious materials. Examples of these cement hydration thermodynamic predictions using GEMS and PHREEQC can be found in the literature $[3,4]$ and are shown in Fig. 1.

PHREEQC is an ion-pairing model written in $\mathrm{C} / \mathrm{C}++$ that is commonly used to perform geochemical predictions between solids, liquids and gases at equilibrium. Using appropriate databases, PHREEQC can perform speciation and saturation-index calculations, simulate kinetically controlled reactions and transport calculations, along with many other reaction types, details of which can be found in Parkhust and Appelo [5].

Thermodynamics has made it possible to predict the assemblages of hydrating cement pastes. Pioneering work in this area by Rothstein [6] and Lothenbach $[3,7,8]$ has demonstrated the capability of thermodynamics to predict the phase assemblages and aqueous pore solution chemistry, amongst other outputs, for most cementitious binders, with appropriate input data including oxide composition, phase proportions, $\mathrm{w} / \mathrm{c}$ ratios and curing temperature. Much of the work using thermodynamics to model cement hydration has utilised the GEMS model [1] to predict the hydrated solid phase assemblage formed from dissolving cement phases over time. Lothenbach's and colleagues' work in developing cement-based databases for modelling hydration [2], coupled with the GEMS software, has made the prediction of solid phase precipitation and aqueous changes over time achievable. GEMS is one of several models available to undertake cement hydration and reaction studies that includes the EQ3/6 [9] and CHESS [10] software packages.

Previous work on modelling cement with limestone includes that by Lothenbach et al. [3] who modelled the addition of $4 \%$ limestone

\footnotetext{
* Corresponding author.
} 


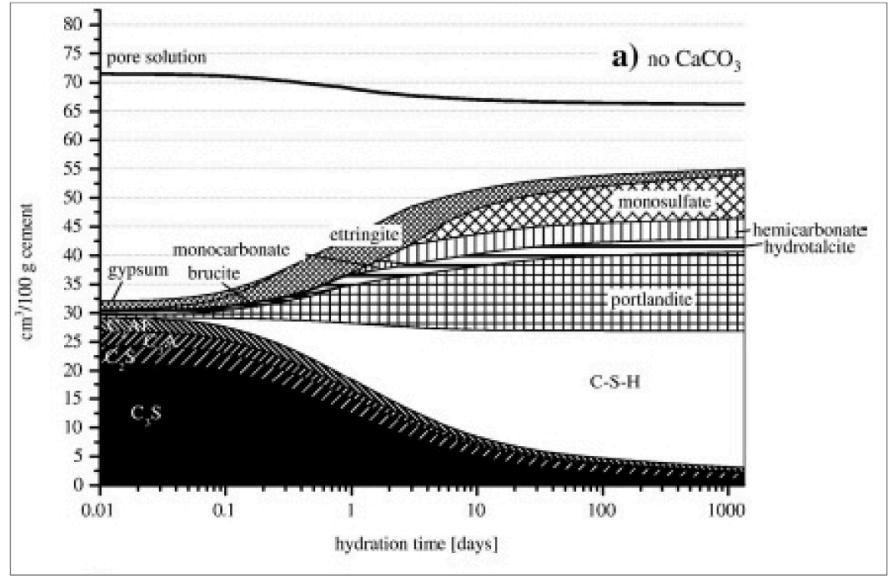

(a)

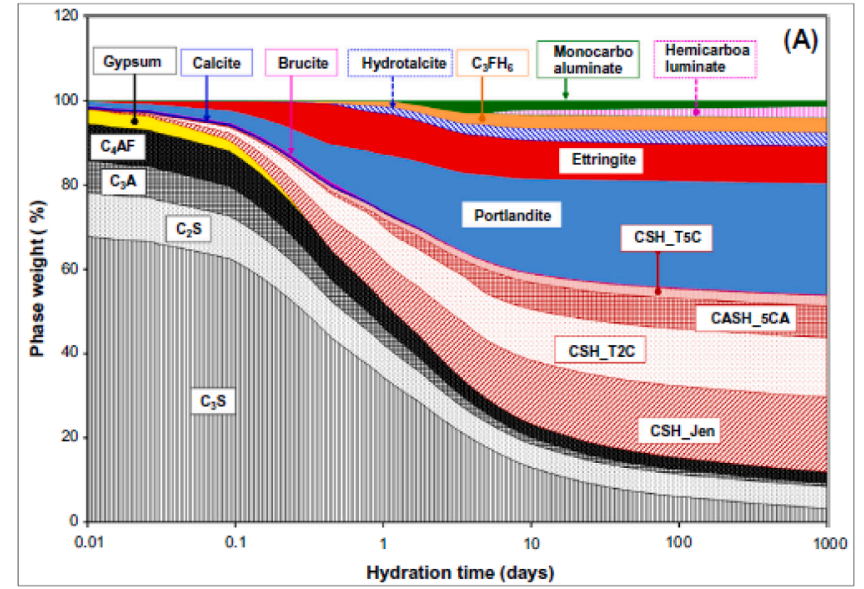

(b)

Fig. 1. Previously modelled phase assemblages using (a) GEMS [3] and (b) PHREEQC [4] for non-limestone cements.

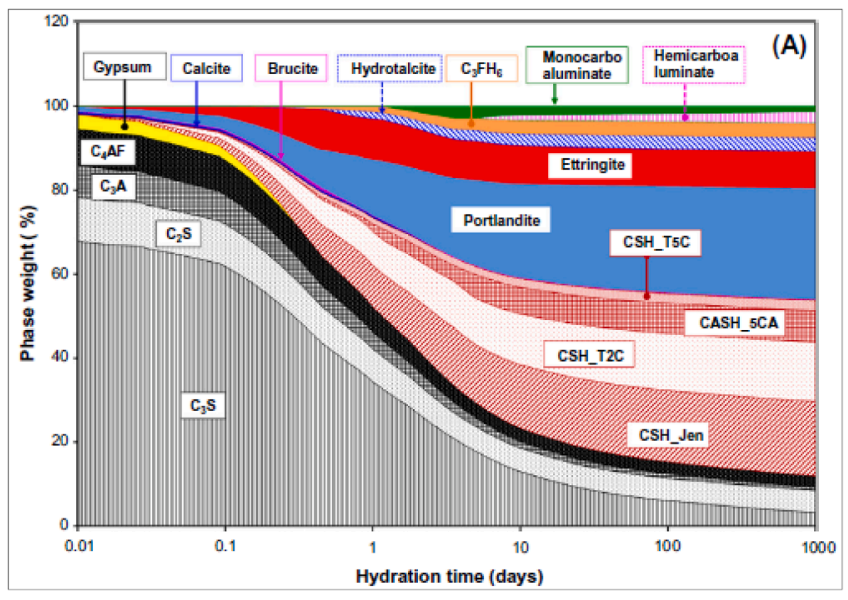

(a)

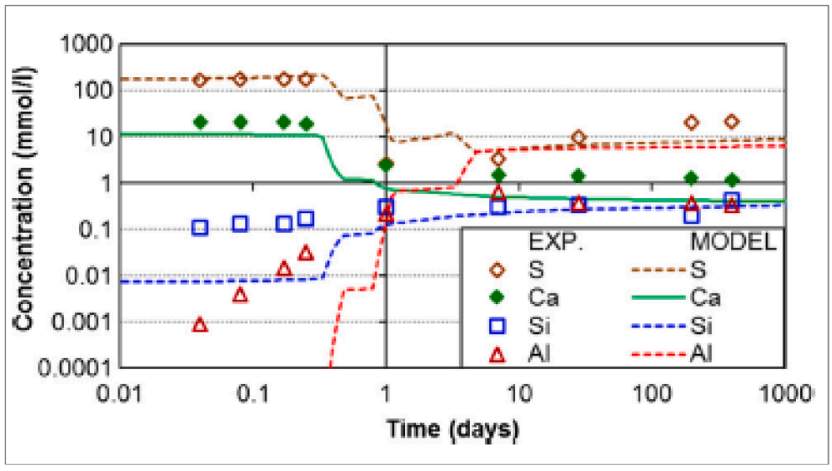

(b)

Fig. 2. (a) Phase assemblage and (b) pore solution chemistry modelling by Elakneswaran et al. [4] for OPC.

powder blended with a Portland cement. This limestone content is within the limits for a CEM I cement but is much lower than the $20 \%$ permissible for a CEM II/A-L under EN197-1 [11] which is investigated here. Bentz [12] modelled limestone additions up to $20 \%$ using the CEMHYD3D cement hydration model by blending a Cement and Concrete Reference Laboratory (CCRL) [13] with a fine limestone powder. Bentz concluded that limestone accelerated cement hydration in lower

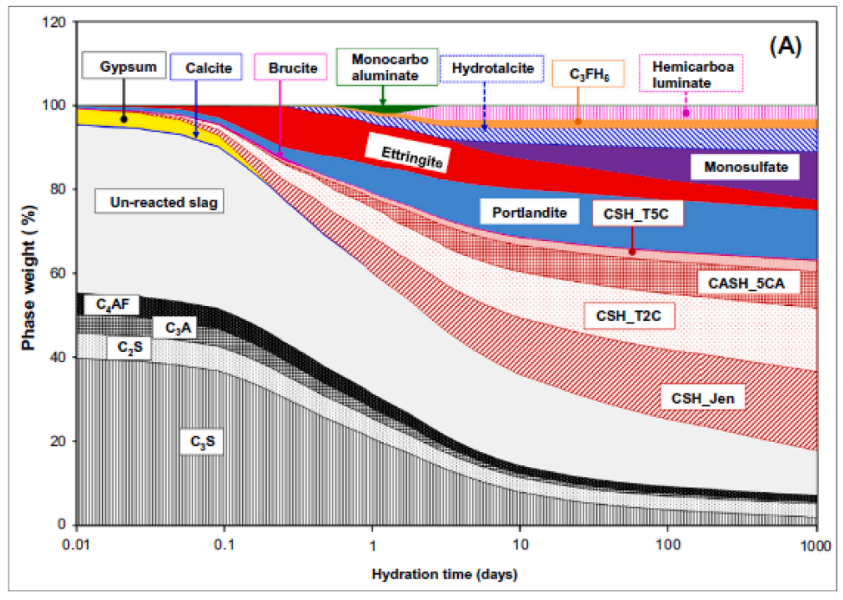

(a)

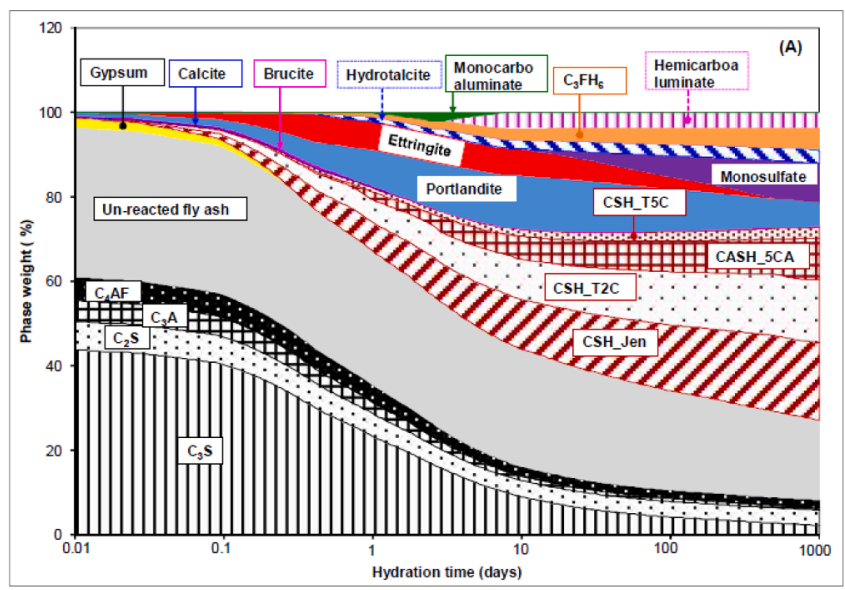

(b)

Fig. 3. Phase assemblage modelling by Elakneswaran et al. [4] and [30] for (a) slag (60:40 GGBS:OPC) and (b) fly ash (35:65 FA:OPC [212,220]).

$\mathrm{w} / \mathrm{c}$ ratio blends by creating additional sites for nucleation and growth of hydration products. He also concluded that up to $20 \%$ limestone powder replacement did not have any detrimental effect on the performance and would help reduce the environmental impact of cement 
Table 1

CEM I and CEM II/A-L oxide proportions.

\begin{tabular}{lllr}
\hline Oxide proportions $(\mathrm{g} / 100 \mathrm{~g}$ cement) & & \\
\hline $\mathrm{CEM} \mathrm{I}$ & & $\mathrm{CEM} \mathrm{II} / \mathrm{A}-\mathrm{L}$ & \\
\hline $\mathrm{SiO}_{2}{ }^{\mathrm{a}}$ & 19.04 & $\mathrm{SiO}_{2}{ }^{\mathrm{a}}$ & 17.5 \\
$\mathrm{Al}_{2} \mathrm{O}_{3}{ }^{\mathrm{a}}$ & 5.01 & $\mathrm{Al}_{2} \mathrm{O}_{3}{ }^{\mathrm{a}}$ & 4.6 \\
$\mathrm{Fe}_{2} \mathrm{O}_{3}{ }^{\mathrm{a}}$ & 2.83 & $\mathrm{Fe}_{2} \mathrm{O}_{3}{ }^{\mathrm{a}}$ & 2.6 \\
$\mathrm{CaO}^{\mathrm{a}}$ & 63.4 & $\mathrm{CaO}^{\mathrm{a}}$ & 62.0 \\
$\mathrm{MgO}^{\mathrm{a}}$ & 2.31 & $\mathrm{MgO}^{\mathrm{a}}$ & 2.3 \\
$\mathrm{Na}_{2} \mathrm{O}^{\mathrm{a}}$ & 0.28 & $\mathrm{Na}_{2} \mathrm{O}^{\mathrm{a}}$ & 0.26 \\
$\mathrm{~K}_{2} \mathrm{O}^{\mathrm{a}}$ & 0.54 & $\mathrm{~K}_{2} \mathrm{O}^{\mathrm{a}}$ & 0.50 \\
$\mathrm{CaO}^{\mathrm{a}}$ free & $\mathrm{CaO}^{\mathrm{b}}$ & $\mathrm{CO}_{2}{ }^{\mathrm{c}}$ & 1.62 \\
$\mathrm{CO}_{2}{ }^{\mathrm{c}}$ & 1.71 & $\mathrm{SO}_{3}{ }^{\mathrm{a}}$ & 6.27 \\
$\mathrm{SO}_{3}{ }^{\mathrm{a}}$ & 1.32 & $\mathrm{Periclase}^{\mathrm{d}}$ & 2.45 \\
$\mathrm{Periclase}^{\mathrm{d}}$ & 2.65 & $\mathrm{LOI}$ & 1.0 \\
$\mathrm{LOI}$ & 1.0 & & 7.22 \\
$\mathrm{Blaine}$ fineness $\left(\mathrm{m}^{2} / \mathrm{kg}\right)$ & & 474 & \\
386 & & & \\
\hline
\end{tabular}

${ }^{\mathrm{a}}$ Calculated using XRF; ${ }^{\mathrm{b}}$ Calculated using titration.

${ }^{\mathrm{c} C a l c u l a t e d}$ from Carbon; ${ }^{\mathrm{d}}$ Calculated using XRD.

production. Mohamed et al. [14] modelled the effect of different limestone additions (5,10,15 and 20\%) using the $\mu$ ic microstructural hydration model and they found, like Bentz [12], that the limestone helps to create additional hydration products to form monocarbonate rather than monosulfate. In all of the above work, limestone powder was blended with cement to form a composite material.

A comprehensive summary of the effects of limestone additions on cement hydration in terms of its mechanical performance, solid hydrate development and pore solution chemistry can be found in [3]. Between 5 and $10 \%$ limestone replacement, there is little effect on the compressive and flexural strength, due to the fine particle size distribution of the powder. Limestone promotes the precipitation of monocarbonate rather than monosulfate over time, which stabilises ettringite and in turn increases the overall volume of the assemblage. Compared with the pore solution of a plain Portland cement, limestone binders have a minor effect. However, the presence of monocarbonate and stable ettringite results in lower aluminium and higher sulfate and carbonate concentrations. Measured heat of hydration curves using isothermal conduction calorimetry show a slightly accelerated rate of cement hydration in the presence of limestone and the presence of additional surfaces for the nucleation and growth of hydration products [15].

This paper will show how PHREEQC can be used to undertake solubility calculations and predict stable hydrate assemblage and solution chemistry during the hydration of commercial CEM I and CEM II/A-L cements, as described in IS EN 197-1 [11] rather than blended powders. Using an appropriate thermodynamic database, there are only very minor differences between the GEMS and PHREEQC predictions, albeit varying in the analysis. This paper will also describe how PHREEQC can be coupled with the HYDCEM model [16] to allow the user to undertake multiple analyses (solubility and solids prediction, phase assemblage programming and aqueous solution chemistry) under one umbrella software upon inputting the cement system data (oxide composition, phase proportions, $\mathrm{w} / \mathrm{c}$ ratios, temperature, etc.). HYDCEM is a cement hydration model developed by the authors that has, most recently, been shown to be capable of predicting phase assemblages by successfully coupling with PHREEQC after details of the hydrating cement have been inputted [17].

\section{PHREEQC geochemical model}

PHREEQC is a long-established model predominantly used in aqueous geochemical calculations [18] but offering great flexibility for use elsewhere. It undertakes its thermodynamic equilibrium calculations by solving equations based on the law of mass action (LMA) at a specified temperature and pressure. It undertakes thermodynamic equilibrium calculations [5,19] to determine if a phase is likely to dissolve or precipitate. This approach is also used by EQ3/6 and CHESS software whereas GEMS undertakes its predictions by minimising the Gibbs free energy of the system under analysis. Both approaches are

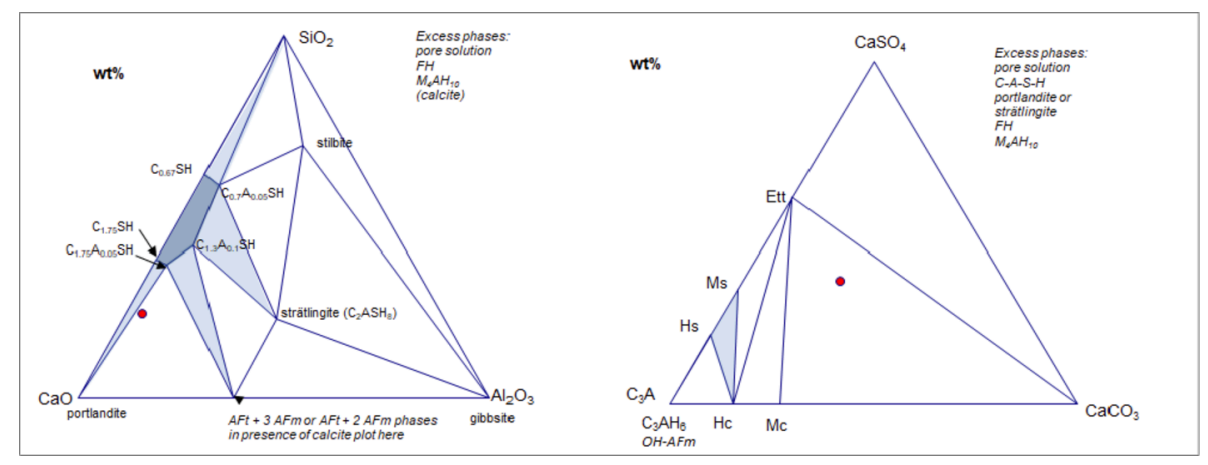

Fig. 4. Ternary diagrams for a CEM I cement.

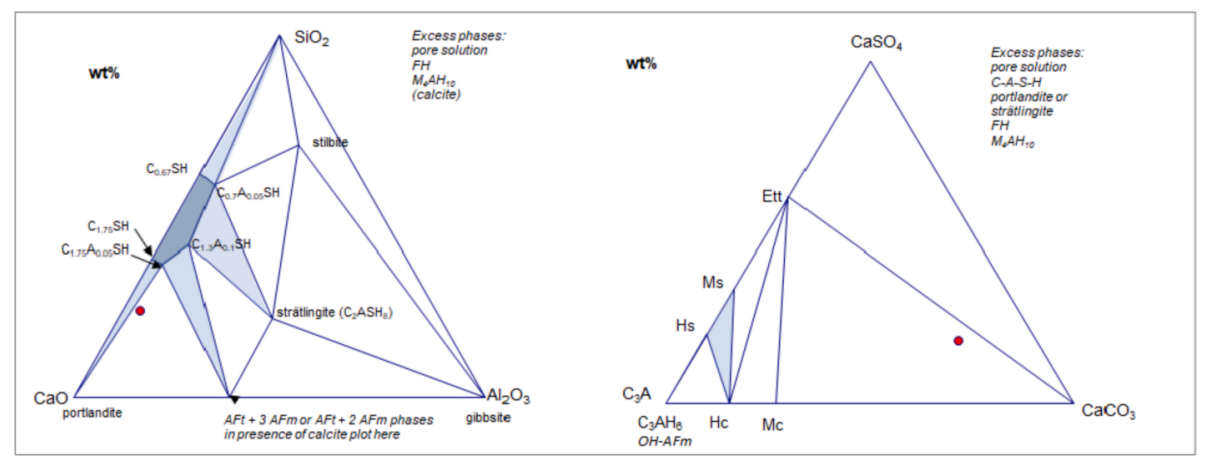

Fig. 5. Ternary diagram for a CEM II/A-L cement. 
Table 2

Normalised phase compositions for the CEM I and CEM IIA-L cements in Figs. 4 and 5.

\begin{tabular}{|c|c|c|c|c|c|c|c|c|c|}
\hline \multicolumn{5}{|c|}{ CEM I cement } & \multicolumn{5}{|c|}{ CEM II/A-L cement } \\
\hline Phase & $\mathrm{g} / 100 \mathrm{~g}$ & $\mathrm{mmol} / 100 \mathrm{~g}$ & Mineral & Moles & Phase & $\mathrm{g} / 100 \mathrm{~g}$ & $\mathrm{mmol} / 100 \mathrm{~g}$ & Mineral & moles \\
\hline $\mathrm{C}_{3} \mathrm{~S}$ & 59.84 & 255.78 & $\mathrm{C}_{3} \mathrm{~S}$ & 0.2621 & $\mathrm{C}_{3} \mathrm{~S}$ & 47.86 & 205.07 & $\mathrm{C}_{3} \mathrm{~S}$ & 0.2096 \\
\hline $\mathrm{C}_{2} \mathrm{~S}$ & 10.78 & 61.11 & $\mathrm{C}_{2} \mathrm{~S}$ & 0.0626 & $\mathrm{C}_{2} \mathrm{~S}$ & 15.17 & 86.19 & $\mathrm{C}_{2} \mathrm{~S}$ & 0.0881 \\
\hline $\mathrm{C}_{3} \mathrm{~A}$ & 8.70 & 31.41 & $\mathrm{C}_{3} \mathrm{~A}$ & 0.0322 & $\mathrm{C}_{3} \mathrm{~A}$ & 7.96 & 28.83 & $\mathrm{C}_{3} \mathrm{~A}$ & 0.0295 \\
\hline $\mathrm{C}_{4} \mathrm{AF}$ & 8.82 & 17.72 & $\mathrm{C}_{4} \mathrm{AF}$ & 0.0182 & $\mathrm{C}_{4} \mathrm{AF}$ & 8.09 & 16.28 & $\mathrm{C}_{4} \mathrm{AF}$ & 0.0166 \\
\hline $\mathrm{CaO}_{-}$free & 1.75 & 30.49 & Gypsum & 0.0265 & $\mathrm{CaO}_{-}$free & 1.66 & 28.89 & Gypsum & 0.0245 \\
\hline $\mathrm{CaCO}_{3}$ & 5.13 & 49.99 & $\mathrm{MgO}$ & 0.0587 & $\mathrm{CaCO}_{3}$ & 14.57 & 142.47 & $\mathrm{MgO}$ & 0.0583 \\
\hline $\mathrm{CaSO}_{4}$ & 4.57 & 25.91 & Calcite & 0.0512 & $\mathrm{CaSO}_{4}$ & 4.21 & 23.94 & Calcite & 0.1456 \\
\hline $\mathrm{K}_{2} \mathrm{SO}_{4}$ & 0.92 & 5.16 & Lime & 0.0312 & $\mathrm{~K}_{2} \mathrm{SO}_{4}$ & 0.85 & 4.78 & Lime & 0.0295 \\
\hline $\mathrm{Na}_{2} \mathrm{SO}_{4}$ & 0.30 & 2.03 & $\mathrm{Na}_{2} \mathrm{O}$ & 0.0025 & $\mathrm{Na}_{2} \mathrm{SO}_{4}$ & 0.27 & 1.89 & $\mathrm{Na}_{2} \mathrm{O}$ & 0.0024 \\
\hline $\mathrm{K}_{2} \mathrm{O}$ & 0.06 & 0.57 & $\mathrm{~K}_{2} \mathrm{O}$ & 0.0006 & $\mathrm{~K}_{2} \mathrm{O}$ & 0.05 & 0.53 & $\mathrm{~K}_{2} \mathrm{O}$ & 0.0005 \\
\hline $\mathrm{Na}_{2} \mathrm{O}$ & 0.16 & 2.48 & $\mathrm{Na}_{2} \mathrm{SO}_{4}$ & 0.0021 & $\mathrm{Na}_{2} \mathrm{O}$ & 0.15 & 2.31 & $\mathrm{Na}_{2} \mathrm{SO}_{4}$ & 0.0019 \\
\hline $\mathrm{MgO}$ & 2.37 & 57.31 & $\mathrm{~K}_{2} \mathrm{SO}_{4}$ & 0.0053 & $\mathrm{MgO}$ & 2.35 & 57.07 & $\mathrm{~K}_{2} \mathrm{SO}_{4}$ & 0.0049 \\
\hline $\mathrm{SO}_{3}$ & 0.11 & 1.40 & $\mathrm{SO}_{3}$ & 0.0014 & $\mathrm{SO}_{3}$ & 0.11 & 1.40 & $\mathrm{SO}_{3}$ & 0.0014 \\
\hline
\end{tabular}

proven to be reliable, with very minor differences in the predictions using the same database.

An IPhreeqc set of modules allows PHREEQC to be coupled with programming languages without the need to read from or write to files [20] through a library. The IPhreeqc COM module can be used by any software that supports the COM interface whereas the $\mathrm{C}++$ class, libraries and dynamic link libraries (DLLs) can be compiled into C-based programmes [20]. Input information and results transfer occurs via the internal computer memory exchange between PHREEQC and the coupled programme. The IPhreeqc module allows PHREEQC to be run within models like HYDCEM simultaneously without having to move between separate models and securing data transfer including results. Coupling PHREEQC with other programmes such as DuCOM [21], a speciation solver [22], COMSOL [23] and EXCEL [4] to model cement hydration has been reported in the literature. In such applications, PHREEQC has proven to be a robust and flexible chemical simulator which is readily coupled to other codes, facilitating chemical predictions as required.

PHREEQC uses Equation (1) $[4,18]$ to determine if a phase is in equilibrium, dissolved or precipitated, where $\mathrm{K}$ is the thermodynamic equilibrium constant for the phase, $\gamma_{i}$ is the ion activity coefficient, $c_{i}$ is the ion concentration (mol/L) and $n_{i}$ is the stoichiometric coefficient of the ion in the phase.

The thermodynamic equilibrium constant for the phase, $\mathrm{K}$, at a given temperature T (in Kelvin) is determined using Equation (2) where $\Delta_{\mathrm{r}} \mathrm{G}_{\mathrm{T}}{ }^{0}$ is the standard Gibbs energy of reaction at temperature T (Equation (3)), $\mathrm{R}$ is the universal gas constant $(8.31451 \mathrm{~J} /(\mathrm{mol} \mathrm{K}))$ and $\Delta_{\mathrm{f}} \mathrm{G}_{\mathrm{T}}{ }^{0}$ is the Gibbs free energy of formation for a species (product or reactant) at a given temperature [4].

$K=\prod_{i}\left(\gamma_{i} c_{i}\right)^{n_{i}}$

$K_{p}=\exp \left(-\frac{\Delta_{f} G_{T}^{0}}{R T}\right)$

$\Delta_{r} G_{T}^{0}=\sum \Delta_{f} G_{T, p r o d u c t s}^{0}-\sum \Delta_{f} G_{T, \text { reactants }}^{0}$

\section{Previous use of PHREEQC for cement hydration modelling}

PHREEQC was used as a sub-model by Elakneswaran and Ishida [24] to assess the behaviour of cementitious materials in aggressive environments. It was coupled with the DuCOM [25] model to solve multispecies transport problems together with a comprehensive set of geochemical reactions as hydration continued. Computed and measured literature data gave good correlations and the authors concluded that coupled platforms could give a reasonable assessment of cementitious materials in aggressive environments. PHREEQC was used to calculate speciation and saturation index, mineral-solution equilibrium, ion- exchange equilibrium and surface-complexation in a variety of aqueous geochemical environments.

The modelling of hydration of ordinary Portland cement (OPC) and ground granulated blast-furnace slag (GGBS) blended cements was undertaken by Elakneswaran et al. [4] using the IPhreeqc module [20] with MS Excel®. PHREEQC was coupled (using the IPhreeqc module [22]) with Excel $\mathbb{\circledR}$ to carry out thermodynamic calculations over time at suitable time-steps. The dissolution rates of the clinker were solved for in Excel ${ }^{\circledR}$ and transferred to PHREEQC (via IPhreeqc) to predict the solution composition and precipitated phases using thermodynamic properties from CEMDATA 07 [3] and others [26]. Examples of the outputs for OPC, GGBS and Fly-ash using this approach are shown in Fig. 2 and Fig. 3. For both GGBS and fly ash, the authors found that the predicted phases assemblages and pore solutions were comparable with measured data in the literature. As shown, the change in phase weight demonstrates how PHREEQC is capable of predicting the phase assemblage over time for plain cements and those containing GGBS and fly-ash.

Follow-on work in similar areas can be found in [27-29] that further shows the suitability of PHREEQC to model either part, or full-hydration of cementitious materials including OPC, GGBS and Fly ash. The following section will present how PHREEQC has been coded into the Notepad ++ for PHREEQC editor to model the hydration of two cement types with different limestone contents. Results from PHREEQC predictions will be compared to those from the established GEMS [1] thermodynamic software which has a proven track record in modelling cementitious systems that have been verified through experimental analysis.

\section{Cement hydration modelling using PHREEQC}

This section will describe a full hydration analysis for CEM I and CEM II/A-L cements with different limestone contents including predictions of which (i) solid phases will precipitate, (ii) phases assemblage, cement clinker dissolution, silicates and aluminate changes over time and (iii) pore solution chemistry changes occur in PHREEQC using the experimentally derived oxide proportions shown in Table 1 [11]. The proportions shown are determined using a combination of XRF, titration and XRD analyses. A CEM I cement consists of at least 95\% clinker with $5 \%$ of minor constituents, such as limestone powder. The CEM II/A-L cement contains circa 15\% limestone additions in accordance with [11].

The hydration of the two cements are modelled with a w/c ratio of 0.5 and a starting temperature of $20{ }^{\circ} \mathrm{C}$. All programming described herein used Notepad ++ software as the PHREEQC editor, which provides a number of useful tools such as auto completion of terms and keywords, coloured numbers, bracket checking, etc. The model will be made up of three separate main input files using appropriate thermodynamic data. Further analyses of the effects of increasing temperature and heat of hydration are also presented. 
Table 3

Thermodynamic data used for the hydration analysis @ $20^{\circ} \mathrm{C}$.

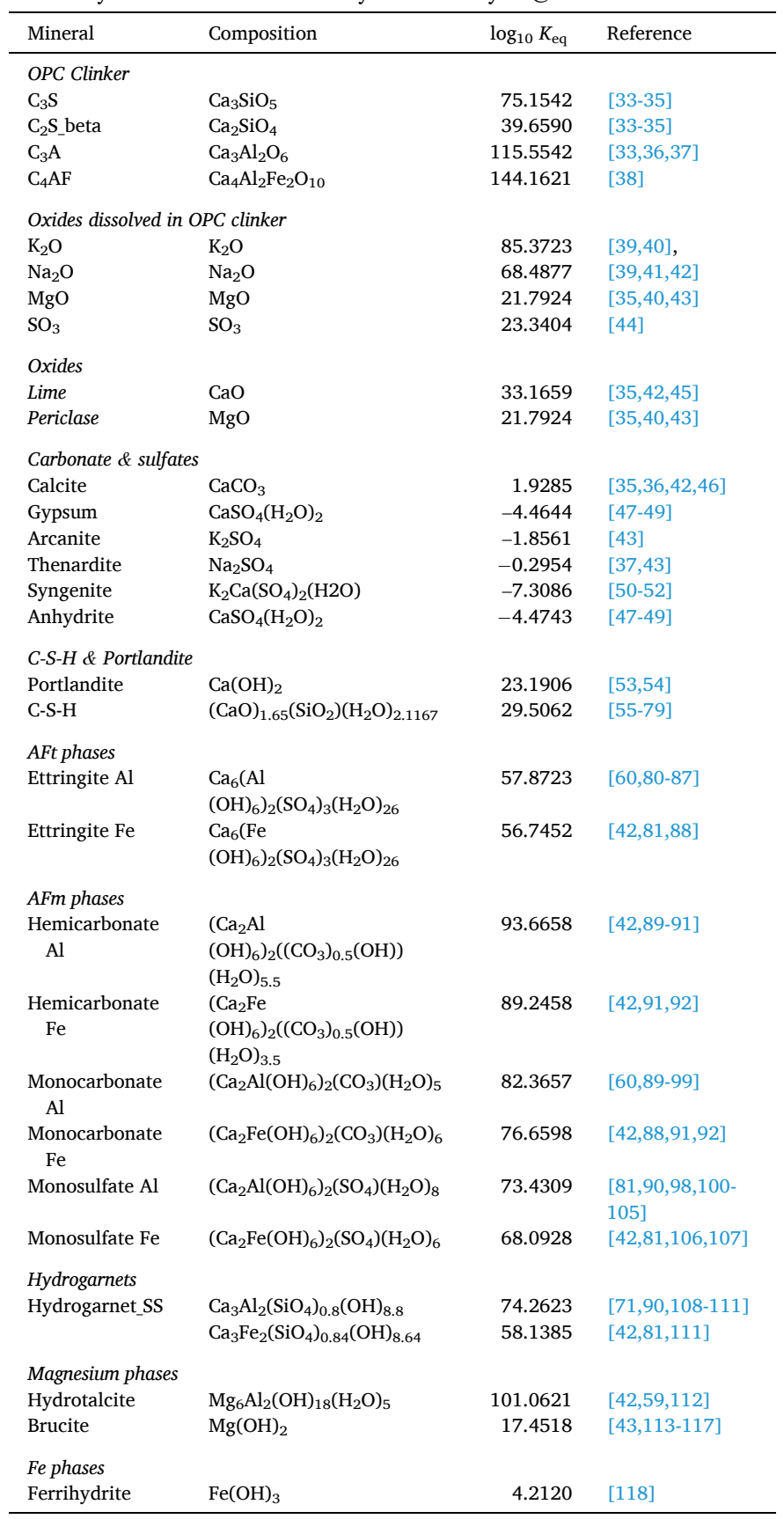

Using Ternary diagrams ([31], free to download from [32]), the cements in Table 1 are expected to form Calcium Silicate Hydrate gel (CS-H), Portlandite and AFm/AFt phases from the diagrams in Fig. 4 and Fig. 5. The higher limestone present in the CEM II/A-L cement is also predicted to contain significantly more $\mathrm{CaCO}_{3}$, as expected.

\subsection{Determining solid phases}

The first step is to convert the OPC oxide proportions (in $\mathrm{g} / 100 \mathrm{~g}$ of cement) in Table 1 into moles, as PHREEQC operates such that each simulation is calculated in terms of molal quantities - that is, moles of substance per kilogram of solution. To do this, the number of moles in each of the oxides is calculated using its molar mass and is distributed in whole or in part to the phase composition shown in Table 2, which is then normalised to $100 \mathrm{~g}$ of cement. The hydrating cement has a w/c
Table 4

Log equilibrium constants, Keq $\left(20^{\circ} \mathrm{C}\right)$ for formation reactions and ion size parameters, åi (̊̊) of aqueous species/complexes.

\begin{tabular}{|c|c|c|c|}
\hline $\begin{array}{l}\text { Aqueous species/ } \\
\text { complex }\end{array}$ & $\log _{10} K_{\mathrm{eq}}{ }^{\text {(a) }}$ & $\begin{array}{l}\stackrel{\circ}{i}_{i} \\
(\AA)\end{array}$ & Reference \\
\hline $\mathrm{Al}(\mathrm{OH})_{2}{ }^{+}$ & -10.8887 & 4.0 & [119] \\
\hline $\mathrm{Al}(\mathrm{OH})_{3}$ & -16.8662 & Set & \\
\hline $\mathrm{Al}(\mathrm{OH})_{4}^{-}$ & -23.4354 & 4.0 & \\
\hline $\mathrm{Al}^{3+}$ & 0 & 9.0 & \\
\hline $\mathrm{AlOH}^{2+}$ & -5.1038 & 4.5 & {$[119,120]$} \\
\hline $\mathrm{AlSiO}(\mathrm{OH})_{3}{ }^{2+}$ & -2.583 & 4.5 & [121-124] \\
\hline $\mathrm{Ca}^{2+}$ & 0 & 6.0 & {$[125,126]$} \\
\hline $\mathrm{CaAl}(\mathrm{OH})_{4}^{+}$ & -21.6869 & 4.0 & [127] \\
\hline $\mathrm{CaCO}_{3}$ & -7.0989 & Set & {$[46,128]$} \\
\hline $\mathrm{CaFe}(\mathrm{OH})_{4}^{+}$ & -12.6075 & 4.0 & [127] \\
\hline $\mathrm{CaHCO}_{3}{ }^{+}$ & 1.0894 & 4.0 & {$[46,129-135]$} \\
\hline $\mathrm{CaOH}^{+}$ & -12.9637 & 4.0 & {$[46,136,137]$} \\
\hline $\mathrm{CaSiO}(\mathrm{OH})_{3}{ }^{+}$ & -8.7884 & 4.0 & {$[128,138,139]$} \\
\hline $\mathrm{CaSiO}_{2}(\mathrm{OH})_{2}$ & -19.5039 & Set & {$[79,127]$} \\
\hline $\mathrm{CaSO}_{4}$ & 2.1018 & Set & {$[140,128]$} \\
\hline $\mathrm{CO}_{2}$ & 6.4245 & Dru & {$[126,141]$} \\
\hline $\mathrm{CO}_{3}^{2-}$ & -10.384 & 4.5 & {$[126,142]$} \\
\hline $\mathrm{Fe}(\mathrm{OH})_{2}{ }^{+}$ & -5.8978 & 4.0 & {$[54,137]$} \\
\hline $\mathrm{Fe}(\mathrm{OH})_{3}$ & -14.5203 & Set & {$[143,144]$} \\
\hline $\mathrm{Fe}(\mathrm{OH})_{4}^{-}$ & -22.5098 & 4.0 & {$[111,143-151]$} \\
\hline $\mathrm{Fe}^{3+}$ & 8.7793 & 9.0 & {$[137,152,153]$} \\
\hline $\mathrm{FeOH}^{2+}$ & -2.32 & 4.5 & {$[54,137]$} \\
\hline $\mathrm{H}^{+}$ & 0 & 9.0 & {$[126]$} \\
\hline $\mathrm{H}_{2}$ & -46.9143 & Dru & {$[141,153]$} \\
\hline $\mathrm{H}_{2} \mathrm{O}$ & 0 & GC & [154-158] \\
\hline $\mathrm{HCO}_{3}^{-}$ & 0 & 4.0 & {$[126,142]$} \\
\hline $\mathrm{HSO}_{4}^{-}$ & 1.9291 & 4.0 & [126] \\
\hline $\mathrm{K}^{+}$ & 0 & 3.0 & {$[125,126]$} \\
\hline $\mathrm{KAl}(\mathrm{OH})_{4}$ & -24.8669 & Set & [159] \\
\hline $\mathrm{KCO}_{3}^{-}$ & -11.1607 & 4.0 & [127] \\
\hline $\mathrm{KFe}(\mathrm{OH})_{4}$ & -14.6174 & Set & \\
\hline $\mathrm{KHCO}_{3}$ & -0.6326 & Set & \\
\hline $\mathrm{KHSO}_{4}$ & -1.6 & Set & {$[128,160]$} \\
\hline $\mathrm{KOH}$ & -15.1046 & Set & [159] \\
\hline $\mathrm{KSiO}(\mathrm{OH})_{3}$ & -10.1018 & Set & [127] \\
\hline $\mathrm{KSiO}_{2}(\mathrm{OH})_{2}^{-}$ & -23.7604 & 4.0 & \\
\hline $\mathrm{KSO}_{4}^{-}$ & 0.8808 & 4.0 & {$[128,161-163]$} \\
\hline $\mathrm{Mg}^{2+}$ & 0 & 8.0 & {$[126,141,164]$} \\
\hline $\operatorname{MgAl}(\mathrm{OH})_{4}^{+}$ & -18.9623 & 4.0 & {$[127]$} \\
\hline $\mathrm{MgCO}_{3}$ & -7.4281 & Set & {$[128,133,165]$} \\
\hline $\mathrm{MgFe}(\mathrm{OH})_{4}^{+}$ & -11.604 & 4.0 & [127] \\
\hline $\mathrm{MgHCO}_{3}{ }^{+}$ & 1.0412 & 4.0 & {$[128,166]$} \\
\hline $\mathrm{MgOH}^{+}$ & -11.9153 & 4.0 & {$[120,137,167-170]$} \\
\hline $\mathrm{MgSiO}(\mathrm{OH})_{3}{ }^{+}$ & -8.5704 & 4.0 & {$[128,138]$} \\
\hline $\mathrm{MgSiO}_{2}(\mathrm{OH})_{2}$ & -8.5704 & Set & {$[128,138]$} \\
\hline $\mathrm{MgSO}_{4}$ & 2.2344 & Set & [171] \\
\hline $\mathrm{Na}^{+}$ & 0 & 4.0 & {$[119,125]$} \\
\hline $\mathrm{NaAl}(\mathrm{OH})_{4}$ & -24.1969 & Set & {$[119]$} \\
\hline $\mathrm{NaCO}_{3}^{-}$ & -9.2323 & 4.0 & {$[130,134,172-175]$} \\
\hline $\mathrm{NaFe}(\mathrm{OH})_{4}$ & -14.0028 & Set & {$[127]$} \\
\hline $\mathrm{NaHCO}_{3}$ & 0.132 & Set & {$[172-176]$} \\
\hline $\mathrm{NaHSO}_{4}$ & -1.3682 & Set & $\begin{array}{l}\text { Using methods described in } \\
\text { [127] }\end{array}$ \\
\hline $\mathrm{NaOH}$ & -14.9528 & Set & {$[119]$} \\
\hline $\mathrm{NaSiO}(\mathrm{OH})_{3}$ & -8.275 & Set & [177] \\
\hline $\mathrm{NaSiO}_{2}(\mathrm{OH})_{2}^{-}$ & -22.5373 & 4.0 & [127] \\
\hline $\mathrm{NaSO}_{4}^{-}$ & 0.9445 & 4.0 & {$[178]$} \\
\hline $\mathrm{O}_{2}$ & $\begin{array}{l}-87.4702 \\
\text { (d) }\end{array}$ & Dru & {$[141,179,126,153]$} \\
\hline $\mathrm{OH}^{-}$ & -14.1741 & 3.5 & {$[125,126]$} \\
\hline $\mathrm{Si}(\mathrm{OH})_{4}$ & 0 & Dru & {$[180-197]$} \\
\hline $\mathrm{SiO}(\mathrm{OH})_{3}^{-}$ & -9.8905 & 4.0 & {$[138,198-209]$} \\
\hline $\mathrm{SiO}_{2}(\mathrm{OH})_{2}^{2-}$ & -23.3917 & 4.5 & {$[203-205,207,209]$} \\
\hline $\mathrm{SO}_{4}^{2-}$ & 0 & 4.0 & {$[125,126]$} \\
\hline
\end{tabular}

ratio of 0.5 so $50 \mathrm{~g}$ of water (or $0.05 \mathrm{~kg}$ ) is added to the system.

The starting $\mathrm{pH}$ is set to 7 but charge balanced at equilibrium to reflect the solution composition. The water content and $\mathrm{pH}$ are input under the SOLUTION keyword in PHREEQC. To determine which solid phases will form, users can specify particular phases and set their saturation index (SI) equal to zero under the EQUILIBRIUM_PHASES 
Table 5

Predicted mass (g) of fully hydrated products.

\begin{tabular}{|c|c|c|c|}
\hline \multirow{2}{*}{$\frac{\text { CEM I }}{\text { Hydration product }}$} & \multirow[b]{2}{*}{ Mass (g) } & \multirow{2}{*}{$\frac{\text { CEM II/A-L }}{\text { Hydration product }}$} & \multirow[b]{2}{*}{ Mass (g) } \\
\hline & & & \\
\hline C-S-H & 61.93 & C-S-H & 56.78 \\
\hline Portlandite & 28.39 & Portlandite & 23.96 \\
\hline Hydrotalcite & 4.34 & Hydrotalcite & 4.31 \\
\hline Monosulfate & 0 & Monosulfate & 0 \\
\hline Monocarbonate & 16.59 & Monocarbonate & 14.60 \\
\hline Ettringite & 13.93 & Ettringite & 13.05 \\
\hline Water & 13.38 & Water & 16.84 \\
\hline
\end{tabular}

keyword. If, following an initial analysis, a solid phase has a negative SI, it is assumed to be under-saturated and will dissolve into the solution. If the SI is positive, the solution is over-saturated and the solid may form. To expedite this, users can specify which solids PHREEQC should consider, rather than all contained in the database.

The thermodynamic data in Table 3 and Table 4 were used for the analysis. Along with setting the SI for the solid phases to zero, the amount of moles of each phase that can dissolve is input. As may be seen for the two cements (Table 5), the predicted hydrates to form include C$\mathrm{S}-\mathrm{H}$, Portlandite, ettringite and monosulfate. Using the SELECTED_OUTPUT and USER_PUNCH keywords, PHREEQC can also output the fully hydrated mass $(\mathrm{g})$ of each solid phase as a *.txt file, for example.

By using these keywords, the complex output files that are produced after successfully running PHREEQC can be summarised into easy-toread output files. These outputs provide a preliminary snapshot of the products of the fully hydrated cement including the final water content. As may be seen in Table 5 monocarbonate is precipitated in place of monosulfate due to the presence of calcite. This is confirmed by a suite of analyses that varied the percentage of $\mathrm{CaCO}_{3}$ in the system, as summarised in Fig. 6(a). As may be seen, the initial formation of monosulfate is replaced by monocarbonate when the proportion of $\mathrm{CaCO}_{3}$ is greater than approximately $1 \%$. This has been studied by others [210] who found similar behaviour using GEMS (Fig. 6(b)).

\subsection{Programming the phase assemblage}

PHREEQC uses the BASIC programming language and statements are written on numbered lines and variables can be defined as needed. The keywords utilised to produce phase assemblages are RATES, KINETICS, INCREMENTAL_REACTIONS, SOLUTION, USER_PUNCH, SELECTED_OUTPUT and USER_GRAPH. The mathematical rate of each cement phase's kinetic reaction is calculated under the RATES keyword using the method developed by Parrott and Killoh [211] for the dissolution of

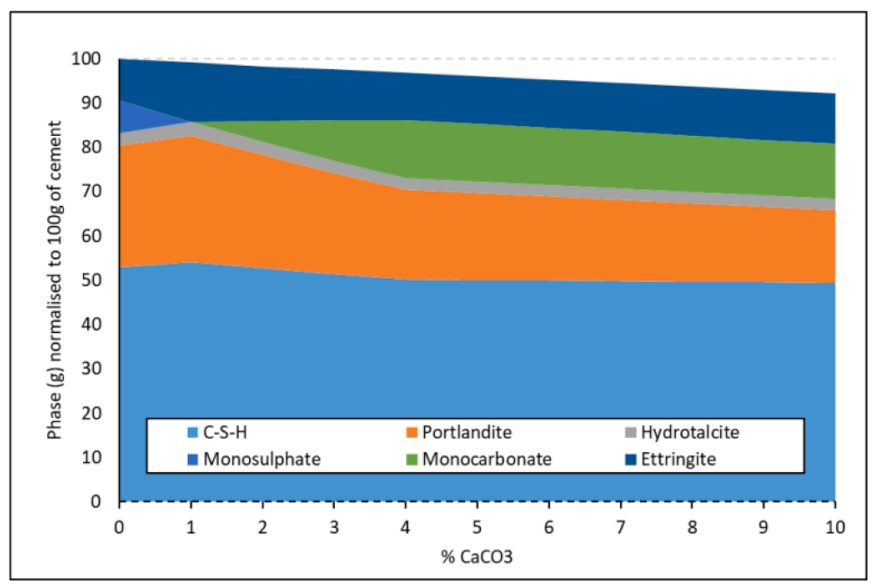

(a) the clinker only. The dissolution of each clinker phase is determined using Equations (4) to (6) which represent nucleation and growth, diffusion and formation of a hydration shell respectively. The controlling rate $(R t)$ is the lowest value from Equations (4-6) for any time step. $A$ and $\mathrm{A}_{0}$ represent the cement surface area and reference surface area $\left(385 \mathrm{~m}^{2} / \mathrm{kg}\right.$ ) respectively. $\mathrm{T}$ and $\mathrm{T}_{0}$ are the curing and reference (of $293.15 \mathrm{~K}$ ) temperatures respectively and the fraction of clinker hydrated at each time step $\left(\alpha_{t}\right)$ is given by $\alpha_{t}=\alpha_{t}-1+\Delta t \cdot \mathrm{R}_{\mathrm{t}-1}$, where time (t) is in days. An arbitrary value of $1 \times 10^{-15}$ is chosen as the first clinker fraction hydrated. The effect of $\mathrm{w} / \mathrm{c}$ ratio is accounted for by using the factor $(f(w / c))$ as given in Equation 7 where $\alpha_{t}$ is the overall degree of hydration of the four clinker phases.

The K, N and $\mathrm{H}$ values used in Equations (4-7) for the three phases are those proposed by Lothenbach et al. [3] as shown in Table 6. The Parrot and Killoh method [211] was coded into PHREEQC using the CALCULATED_VALUES and RATES keywords with the parameters in Table 6. The kinetic parameters for the reactions are defined in the KINETICS data block. It should be highlighted that while the addition of limestone can affect the rate of clinker dissolution over time, as discussed above, it has not been accounted for here as currently no numerical/modelling method exists to predict its effect over time. Also, it is assumed that the volume of calcite in the resulting phase assemblages remains constant throughout.

$R_{t}=\frac{K}{N}\left(1-\alpha_{t}\right)\left(-\ln \left(1-\alpha_{t}\right)\right)^{(1-N)} \cdot \frac{\mathrm{A}}{\mathrm{A}_{0}} \cdot \exp \left[\frac{\mathrm{E}_{\mathrm{a}}^{\mathrm{m}}}{\mathrm{R}}\left(\frac{1}{\mathrm{~T}}-\frac{1}{\mathrm{~T}_{0}}\right)\right] \cdot\left(\frac{\mathrm{RH}-0.55}{0.45}\right)^{4} \cdot \mathrm{f}\left(\frac{\mathrm{w}}{\mathrm{c}}\right)$

$R_{t}=\frac{K\left(1-\alpha_{t}\right)^{\frac{2}{3}}}{1-\left(1-\alpha_{t}\right)^{\frac{1}{3}}} \cdot \exp \left[\frac{\mathrm{E}_{\mathrm{a}}^{\mathrm{m}}}{\mathrm{R}}\left(\frac{1}{\mathrm{~T}}-\frac{1}{\mathrm{~T}_{0}}\right)\right] \cdot\left(\frac{\mathrm{RH}-0.55}{0.45}\right){ }^{4} \cdot \mathrm{f}\left(\frac{\mathrm{W}}{\mathrm{c}}\right)$

$R_{t}=K\left(1-\alpha_{t}\right)^{N} \cdot \exp \left[\frac{\mathrm{E}_{\mathrm{a}}^{\mathrm{m}}}{\mathrm{R}}\left(\frac{1}{\mathrm{~T}}-\frac{1}{\mathrm{~T}_{0}}\right)\right] \cdot\left(\frac{\mathrm{RH}-0.55}{0.45}\right)^{4} \cdot \mathrm{f}\left(\frac{\mathrm{W}}{\mathrm{c}}\right)$

Table 6

Parameters used in the Parrot and Killoh degree of hydration analysis [3].

\begin{tabular}{lllll}
\hline Parameter & $\mathrm{C}_{3} \mathrm{~S}$ & $\mathrm{C}_{2} \mathrm{~S}$ & $\mathrm{C}_{3} \mathrm{~A}$ & $\mathrm{C}_{4} \mathrm{AF}$ \\
\hline $\mathrm{K}^{1}$ & 1.5 & 0.5 & 1.0 & 0.37 \\
$\mathrm{~N}^{1}$ & 0.7 & 1.0 & 0.85 & 0.7 \\
$\mathrm{H}$ & 1.8 & 1.35 & 1.60 & 1.45 \\
$\mathrm{~K}^{2}$ & 1.1 & 0.7 & 1.0 & 0.4 \\
$\mathrm{~N}^{2}$ & 3.3 & 5.0 & 3.2 & 3.7 \\
$\mathrm{~K}^{3}$ & 0.05 & 0.02 & 0.04 & 0.015 \\
$\mathrm{Ea}(\mathrm{J} / \mathrm{mol})$ & 41,570 & 20,785 & 54,040 & 34,087 \\
\hline
\end{tabular}

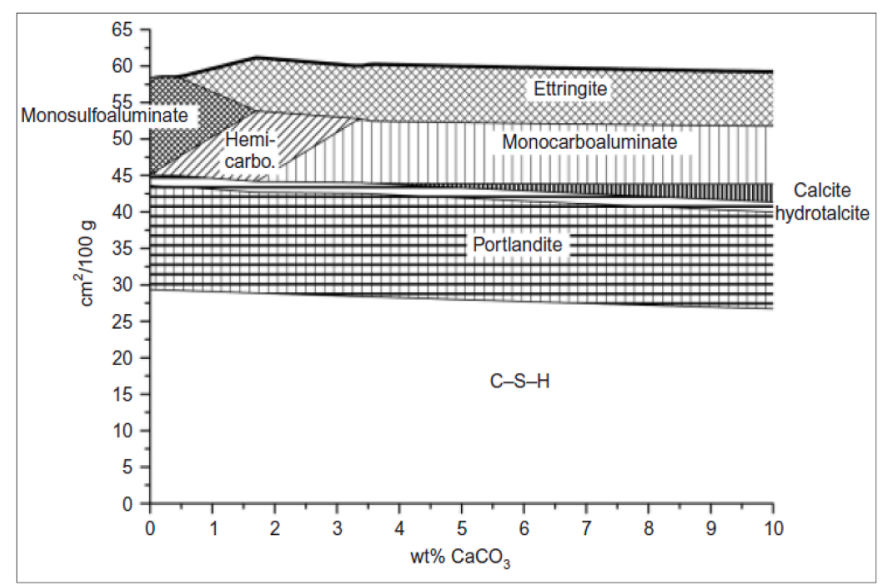

(b)

Fig. 6. Effect of $\mathrm{CaCO}_{3}$ on the behaviour of hydrating cements by (a) PHREEQC and (b) GEMS [210] (Different cements used). 


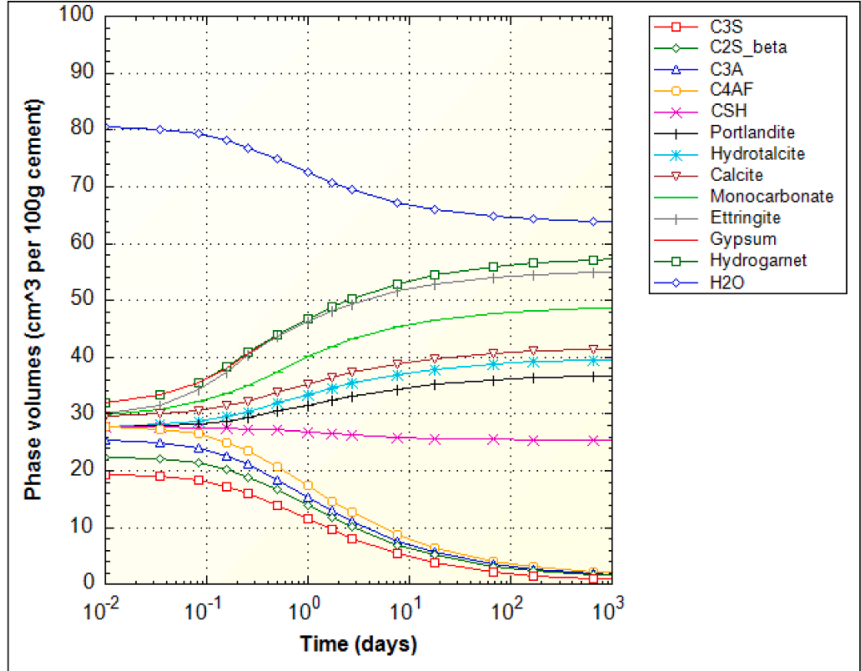

Phase assemblage for the CEM I cement

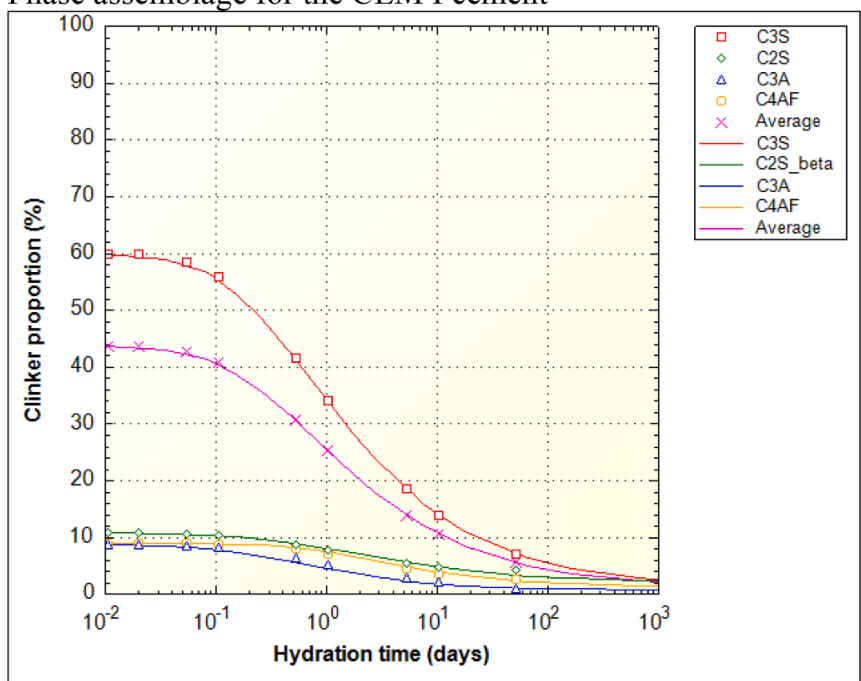

Clinker dissolution for the CEM I cement

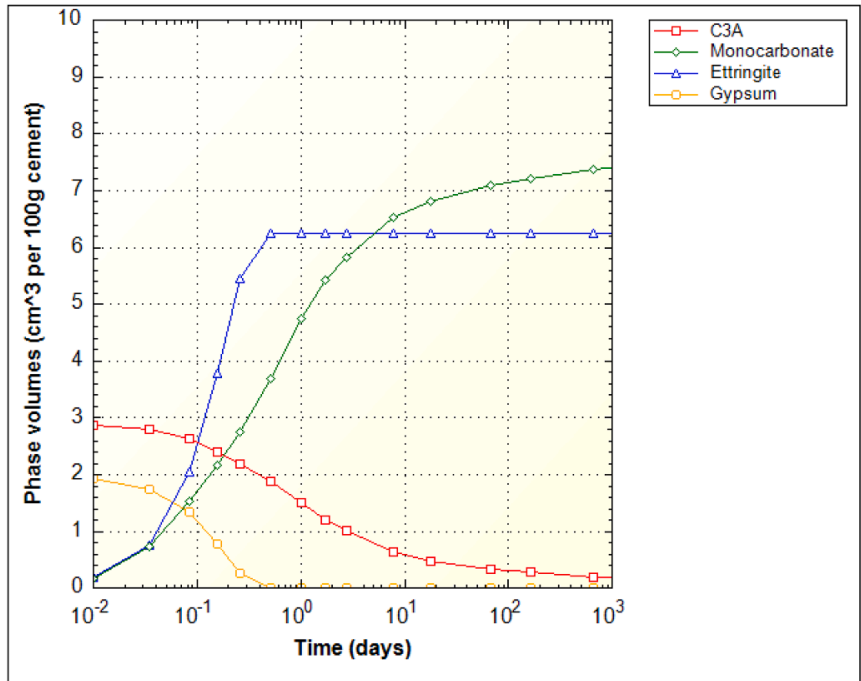

Aluminate phase CEM I cement

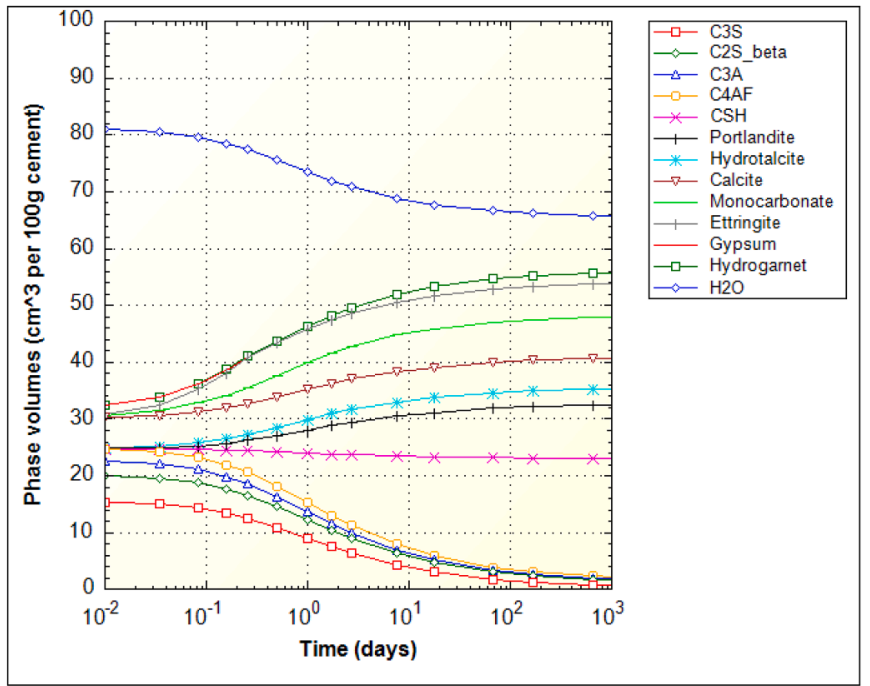

Phase assemblage for the CEM II/A-L cement

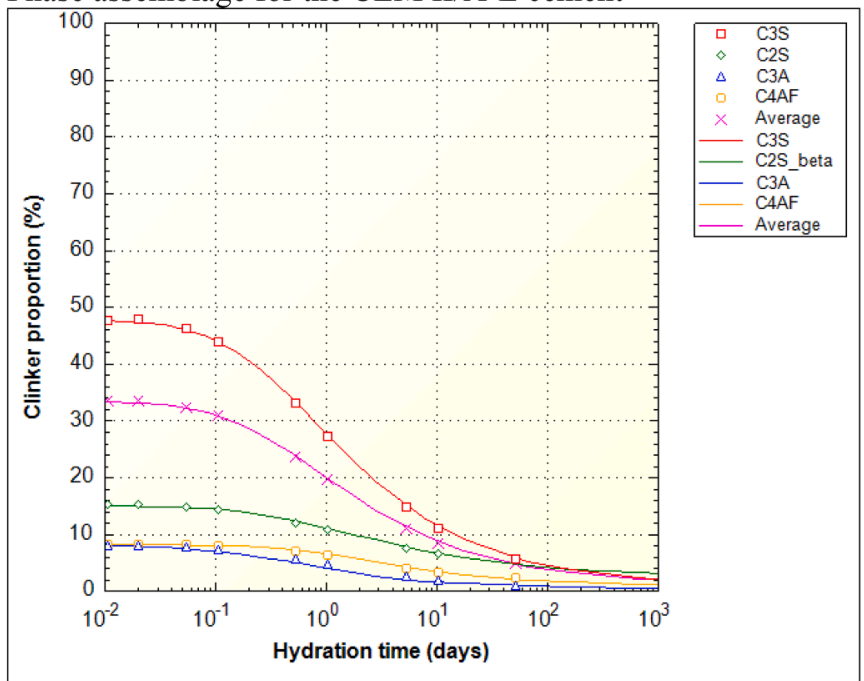

Clinker dissolution for the CEM II/A-L cement

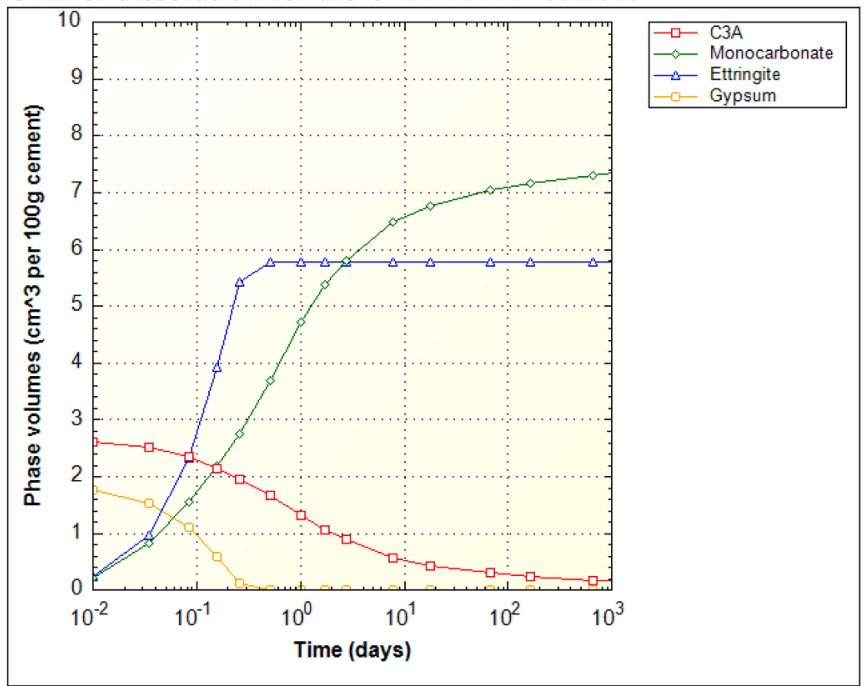

Aluminate phase CEM II/A-L cement

Fig. 7. PHREEQC calculated phase assemblages, clinker dissolution and aluminate phases for the CEM I and CEM II/A-L cement described in Table 1. 


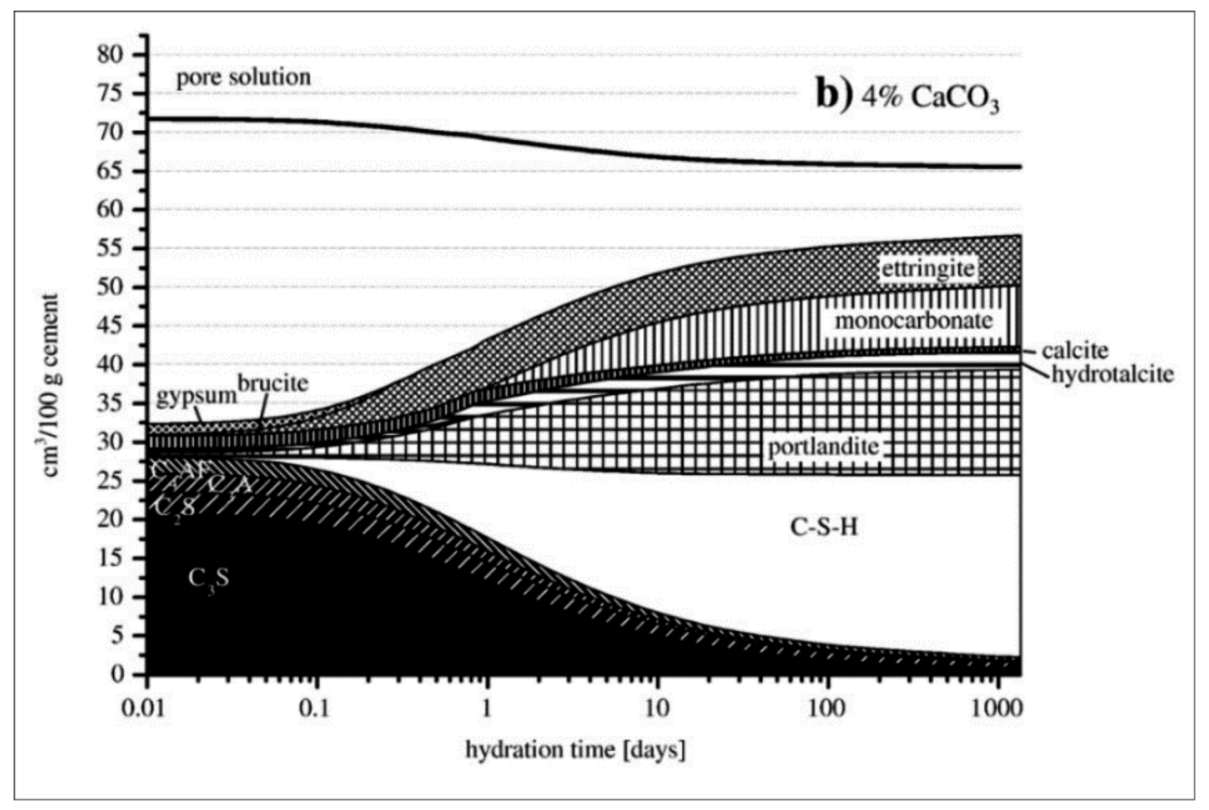

Fig. 8. Phase assemblage using the GEMS thermodynamic model for a cement with a limestone replacement level of $4 \%$ by weight [3].

$f(w / c)=\left(1+3.333 *\left(H * w / c-\alpha_{t}\right)\right)^{4} ; \alpha_{t} H * w / c$

Here, the initial moles of the reactant $\left(\mathrm{C}_{3} \mathrm{~S}, \mathrm{C}_{2} \mathrm{~S}\right.$, etc.) calculated are added to the phase name (also $\mathrm{C}_{3} \mathrm{~S}$ or Alite, etc.). Also provided in the KINETICS data block are the steps (here 0.01 to 1,000 days) and interval (step_divide) of the analysis. Steps defines the time steps to integrate the rate expressions(s). The step_divide input is used for the integration calculations by the Runge-Kutta solver [18]. The keyword INCREMENTAL_REACTIONS is set as true in this analysis to provide an incremental amount of reaction and time. The SOLUTION data block inputs the water content ( $50 \mathrm{~g}$ for a $\mathrm{w} / \mathrm{c}$ ratio of 0.5 ) and curing temperature $\left(20^{\circ} \mathrm{C}\right)$.

The main programming code is within the USER_GRAPH data block and outputs the results. The volume of each predicted hydration phase is calculated over time. The code below shows an example of the calculations undertaken to determine the volume of Portlandite based on the reaction equations for the two silicates phases, where 150 is the BASIC line number, rAli and rBeli are the Alite and Belite rates of reaction, 1.3 and 0.3 are the molar reaction ratios of $\mathrm{C}_{3} \mathrm{~S}$ and $\mathrm{C}_{2} \mathrm{~S}\left(\mathrm{C}_{3} \mathrm{~S}+5.3 \mathrm{H} \rightarrow \mathrm{C}-\mathrm{S}\right.$ $\mathrm{H}+1.3 \mathrm{CH} ; \mathrm{C}_{2} \mathrm{~S}+4.3 \mathrm{H} \rightarrow \mathrm{C}-\mathrm{S}-\mathrm{H}+0.3 \mathrm{CH}$ ) respectively and 33.060 is the molar volume $\left(\mathrm{cm}^{3} / \mathrm{mol}\right)$. The full list of reaction equations used in this work are given in Equations (8) to (15).

150 V_Portlandite $=(($ rAli $* 1.3)+($ rBeli $* 0.3)) * 33.06$

$$
\begin{aligned}
& 1.0 C_{3} S+5.3 H \rightarrow 1.0 C S H+1.3 C H \\
& 1.0 C_{2} S+4.3 H \rightarrow 1.0 C S H+0.3 C H \\
& 1.0 C_{3} A+6.0 H \rightarrow 1.0 C_{3} A H_{6} \\
& 1.0 C_{3} A+3.0 C \$ H_{2}+26 H \rightarrow 1.0 C_{6} A \$_{3} H_{32} \\
& 2.0 C_{3} A+1.0 C_{6} A \$_{3} H_{32}+4 H \rightarrow 3.0 C_{4} A \$ H_{12} \\
& 4 M g O+1.0 A l(O H)_{4}+H \rightarrow 1 M_{4} A H_{10} \\
& 3.0 C_{4} A S H_{12}+2.0 C_{a} C_{3}+18 H \rightarrow C_{6} A S H_{32}+2.0 C_{4} A C H_{11} \\
& C_{3} A+0.5 C H+0.5 C_{a} C_{3}+11.5 H \rightarrow C_{4} A C_{0.5} H_{12}
\end{aligned}
$$

The calculations continue iteratively for the various reactions using the predicted solids from the previous analysis. The outputs include the phase assemblages over time for the CEM I and CEM II/A-L cements, as shown in Fig. 7.

As may be seen, in both cements, gypsum is completely dissolved within 7-8 h, the monocarbonate phase precipitates and ettringite remains stable over time. As brucite was not predicted to form (as described earlier), only the increase in hydrotalcite is considered further as the 'sink' for magnesium. Finally, as ettringite remains present in the system, hydrogarnet growth is constrained. In this way, the hydrate mineral assemblage is defined by maintaining thermodynamic equilibrium between the solids and their pore solution at each incremental stage of reaction. There is also good agreement between the clinker dissolution calculated by PHREEQC and [3]. The volume of both cements is similar but, with more clinker present in the CEM I, it is likely that it will yield slightly lower porosities and higher mortar compressive strengths over time [213]. As expected, there is more calcite $\left(\mathrm{CaCO}_{3}\right)$ in the CEM II/A-L assemblage as up to $14 \%$ is permitted for CEM II/A-L binders compared to 5\% for CEM I, as shown in Table 2 .

The predictions are similar to those obtained by Lothenbach et al. [3] 1 for cements with a limestone percentage of $4 \%$ by weight (see Fig. 8). Similarly, monocarbonate replaces monosulfate and ettringite is stable.

\subsection{Modelling pore solution chemistry}

Modelling the changes in the aqueous solution in PHREEQC is via the PHASES, SOLUTION, EQUILIBRIUM_PHASES, KINETICS and INCREMENTAL_REACTIONS data blocks, as previously described above. The calculations are based on the assumption that the sulphates $\left(\mathrm{Na}_{2} \mathrm{SO}_{4}\right.$, $\mathrm{K}_{2} \mathrm{SO}_{4}$, $\mathrm{CaSO}_{4} /$ gypsum), free lime (CaO_free) and calcite react instantaneously upon contact with water. The cement phases $\left(\mathrm{C}_{3} \mathrm{~S}, \mathrm{C}_{2} \mathrm{~S}\right.$, etc.), $\mathrm{K}_{2} \mathrm{O}$ and $\mathrm{Na}_{2} \mathrm{O}$ are slower to react. The analysis required the computation of element concentrations, namely $\mathrm{Na}, \mathrm{Ca}, \mathrm{K}, \mathrm{OH}-, \mathrm{Al}, \mathrm{Fe}, \mathrm{S}$ and $\mathrm{Si}$ in units of $\mathrm{mmol} / \mathrm{kg}$ water as well as the changing $\mathrm{pH}$ over $1,000 \mathrm{~h}$ of hydration for the cements described in Table 1. In Fig. 9, PHREEQC, unsurprisingly, models quite well the change in aqueous solution chemistry over time as it was originally designed to model the chemistry changes of aqueous solutions. As may be seen in Fig. 10, the predictions are similar to those measured and obtained using GEMS, which compared well with measured pore solution concentrations, thereby providing confidence in the PHREEQC predictions.

As may be seen in Fig. 9, the pore solution contains high levels of potassium and sulfate. The calcium, hydroxide and sulfate contents are 

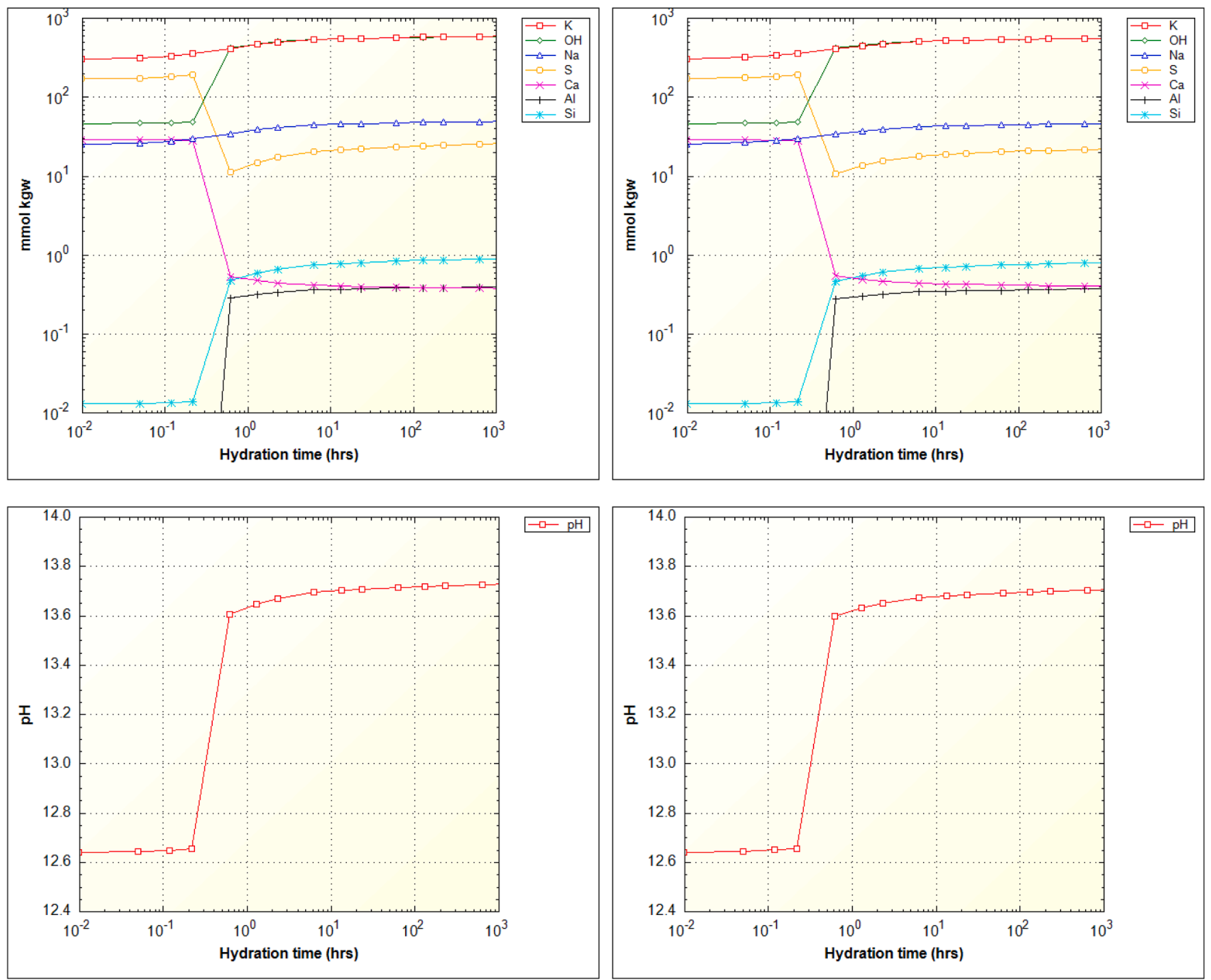

Fig. 9. Modelled pore solution chemistry and $\mathrm{pH}$ over time for the CEM I and CEM II/A-L cements.

strongly influenced by the precipitation/dissolution of gypsum and portlandite, ettringite and C-S-H. There is a marked shift in chemistry, particularly the calcium and sulphates as gypsum is depleted and the system reaches equilibrium with further precipitation of the hydrate solids. Despite the higher calcite content in the CEM II/A-L cement, there is little difference between it and the CEM I pore solution chemistry. However, comparing with OPC systems [8], there are some differences in the sulfate and aluminium concentrations due to the precipitation of monocarbonate and the stable behaviour in ettringite, whereas the presence of monosulfate would lead to higher aluminium and lower sulfate and carbonate concentrations [3].

The pore chemistry and $\mathrm{pH}$ are quite similar for both cements with only minor differences throughout. Previous work on modelling pore chemistry in hydrating cements concluded that the solution is oversaturated with respect to gypsum, portlandite and ettringite, particularly within the first $12 \mathrm{~h}$ [8]. Similar to that work, anhydrite $\left(\mathrm{CaSO}_{4}\right)$ is referred to here as gypsum. When the gypsum is depleted, there is sudden change in the pore chemistry due to the oversaturation of sulphates in solution.

\subsection{Modelling the heat of hydration}

The output from the dissolution of the cement clinker, gypsum and ettringite has been used to predict the rate and cumulative heat of hydration over 1,000 days. This work was aimed at including the second peak or shoulder which is due to sulphates previously bound to the C-S$\mathrm{H}$ dissolving into solution and creating the environment for a second release of heat. Previous work to model the heat of hydration by Jensen et al. [214,215] and Hesse et al. [216] concluded that only the silicates and aluminates contributed significantly to the heat of hydration using the molar reaction equations for $\mathrm{C}_{3} \mathrm{~S}$ (Equation (16)) and the hydration of $\mathrm{C}_{3} \mathrm{~A}$ and dissolution of gypsum to form ettringite (Equation (17)). The enthalpies of reaction of dissolution and precipitation reactions used by Jensen et al. [214] are given in Table 7. It is postulated here that the heat of hydration is driven by Equations (16) and (17) but the hydration of $\mathrm{C}_{2} \mathrm{~S}$ (Equation (18)) with an enthalpy of $262 \mathrm{~J} / \mathrm{g}$ [16] also has an influence on the overall heat produced.

For the two cements analysed, there appears to be a slightly higher and earlier peak $(\sim 15.5 \mathrm{~J} / \mathrm{hr} .100 \mathrm{~g}$ of cement) but lower cumulative heat ( $\sim 370 \mathrm{~J} / 100 \mathrm{~g}$ of cement) in the CEM II/A-L than CEM I ( $\sim 14.5 \mathrm{~J} /$ hr. $100 \mathrm{~g}$ of cement) and ( $\sim 220 \mathrm{~J} / 100 \mathrm{~g}$ of cement)) respectively. This is likely to be due to the higher calcite proportion in the CEM II/A-L cement (5.13 $\mathrm{g}$ and $14.57 \mathrm{~g}$ in CEM I and CEM II/A-L respectively, Table 2). It has been shown in the literature [3] that binders with greater limestone contents will generate slightly higher rates of heat evolution over the initial $8-10 \mathrm{~h}$ than plain cement. This is due to limestone 


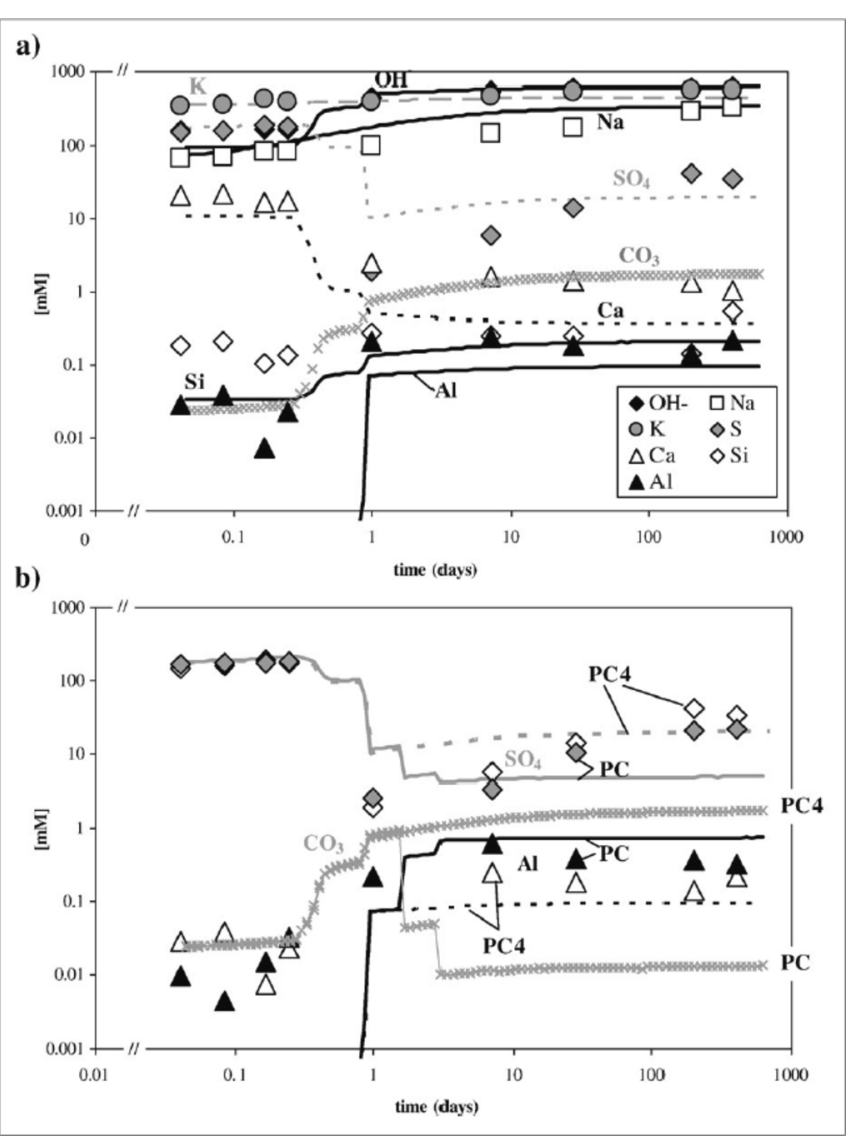

Fig. 10. GEMS predicted and experimentally measured pore solution concentrations with a $4 \%$ by weight limestone addition (PC4) and without (PC) [3].

Table 7

Enthalpies of reaction of dissolution and precipitation reactions [214].

\begin{tabular}{ll}
\hline Reaction & Enthalpy (J/g) \\
\hline Equation (11) Silicate reaction & 561 \\
Equation (12) dissolution of C3A & 868 \\
Equation (12) dissolution of anhydrite & 52 \\
Equation (12) precipitation of ettringite & 214 \\
\hline
\end{tabular}

creating more sites for nucleation and growth of hydration products. However, over time, the cumulative heat evolution is lower.

$\mathrm{C}_{3} \mathrm{~S}+5.3 \mathrm{H} \rightarrow \mathrm{C}_{1.7} \mathrm{SH}_{2.6}+1.3 \mathrm{CH}$

$C_{3} \mathrm{~A}+3$ Gypsum $+26 \mathrm{H} \rightarrow C_{6} A \$_{3} H_{32}($ Ettringite $)$

$\mathrm{C}_{2} \mathrm{~S}+4.3 \mathrm{H} \rightarrow \mathrm{C}_{1.7} \mathrm{SH}_{2.6}+0.3 \mathrm{CH}$

The heat of hydration curves in Fig. 11 were developed using the clinker dissolution (in $\mathrm{g}$ ) determined by PHREEQC and the enthalpies of reaction for Equations (8)-(10). No account is taken of the heat produced by the precipitation of ettringite in Equation (9). Also, it is assumed that the reaction of the $\mathrm{C}_{3} \mathrm{~A}$ in Equation (9) is restrained until the gypsum is dissolved into solution. As may be seen in Fig. 11, the predicted rate and cumulative heat of hydration is reasonable and also clearly demonstrates the second peak or shoulder at approximately 1 day relative to the silicate's heat evolution. Examples of measured heat flow rates from the literature are shown in Fig. 12 in which they all peak at between 8 and $12 \mathrm{~h}$, with the second peak occurring at approximately $15 \mathrm{~h}$.

\subsection{Modelling the effect of temperature on hydration}

PHREEQC can also undertake an analysis over a range of temperatures $\left(0-60{ }^{\circ} \mathrm{C}\right.$, for example) using the REACTION_TEMPERATURE keyword. The range of temperatures to be investigated are inputted and examined using the USER_GRAPH output facility. Previous studies in this area using GEMS [106,210] demonstrated that at approximately $48{ }^{\circ} \mathrm{C}$ (Fig. 13), both ettringite and monocarbonate were unstable relative to monosulfate for a range of cements analysed. Using the CEM I and CEM II/A-L cements described above, an analysis was performed to investigate their predicted thermodynamic behaviour from 0 to $60{ }^{\circ} \mathrm{C}$. As shown in Fig. 14 for the CEM I and CEM II/A-L cements, the change in stability of monocarbonate and ettringite with respect to monosulfate occurs at approximately $42{ }^{\circ} \mathrm{C}$. In both cases, there is an accompanying reduction in volume above $42{ }^{\circ} \mathrm{C}$, especially in the CEM II/A-L cement. While most concrete curing takes place around $20{ }^{\circ} \mathrm{C}$ in temperate climates, prefabrication often employs much higher temperatures that may cause a slight reduction in compressive strength as the monocarbonate and ettringite are converted to monosulfate with a corresponding drop in overall volume.

\section{Discussion}

It is clear that PHREEQC can reliably predict the formation of solid hydrates in a cement/limestone system, model the hydration of cement clinker phases, provide a phase assemblage plot over time and forecast the changing element chemical concentrations in the aqueous solution. It has the capability to model the effect of changing temperature on the phase behaviour as well as estimating the heat of hydration over time. However, to perform the above suite of calculations, four separate input files had to be prepared and analysed. It would be much more convenient to couple the PHREEQC analysis within a bespoke software platform that could provide a supporting/front end capability for user input along with facilitating a full PHREEQC analysis as described above. This software could also perform some preliminary calculations that feed into PHREEQC, such as converting the oxide contents into the normalised phase compositions in Table 2. These input variables could then be transferred to PHREEQC by the supporting software. The heat of hydration predictions could be done in a similar way.

Work is underway by the authors to develop Version 4 of the HYDCEM model $[16,217,218]$ as a single platform to simulate the full hydration for cements with and without limestone upon input of appropriate data, such as oxide proportions, the w/c ratio and curing temperature, along with the Blaine fineness. Previously, HYDCEM produced its phase assemblages by employing volume stoichiometries from molar ratio reactions. Version 4 will be capable of maintaining thermodynamic equilibrium between the hydrates and their common pore solution at each reaction step. This will provide a more robust and realistic simulation of cement hydration than those of previous versions and allow a much wider range of blended cements to be considered.

The authors have previously examined the relationship between the degree of hydration, as predicted by the Parrot and Killoh method [211], and the compressive strength, using the Powers 'gel space' model [219]. Comparisons between the predicted and measured compressive strength to BS EN 196 [220] using European cements are promising using appropriate values in the Powers model. More work is underway to relate the predicted porosities during hydration to measured compressive strengths of mortars. Furthermore, work on heat of hydration predictions over time using thermodynamic data predictions is also underway.

\section{Conclusions}

The conceptual model employed to undertake the simulations presented in this paper operates on the basis that each step of the hydration involves a rapid re-establishment of thermodynamic equilibrium 

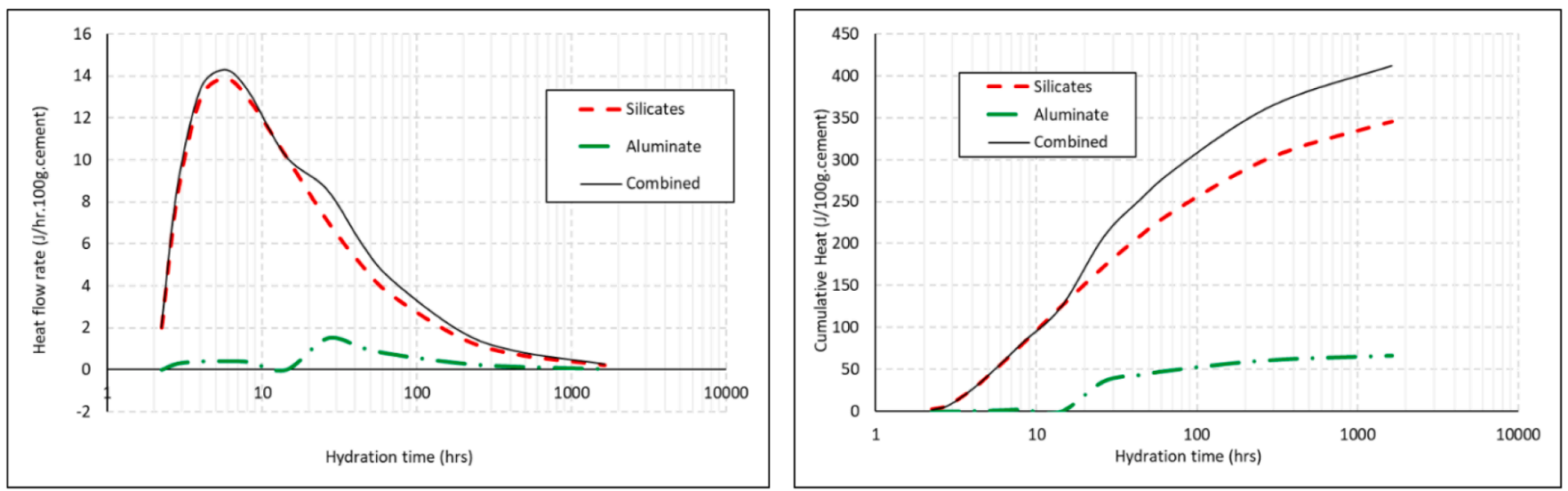

CEM I cement rate and cumulative heat of hydration
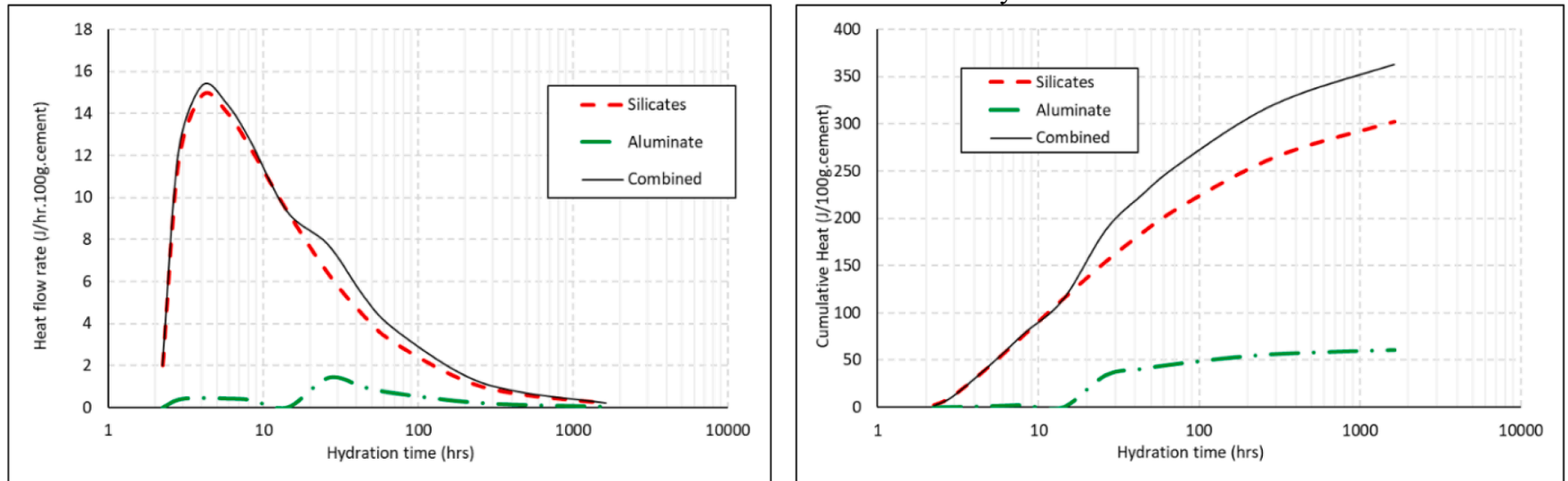

CEM II/A-L cement rate and cumulative heat of hydration

Fig. 11. Heat of hydration curves for the CEM I and CEM II/A-L cements.

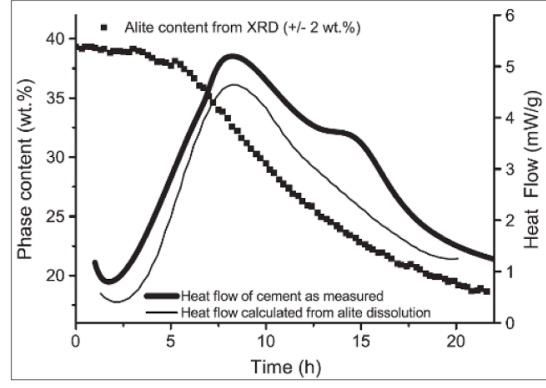

(a)

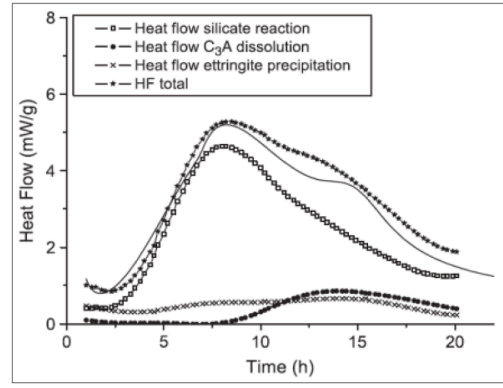

(b)

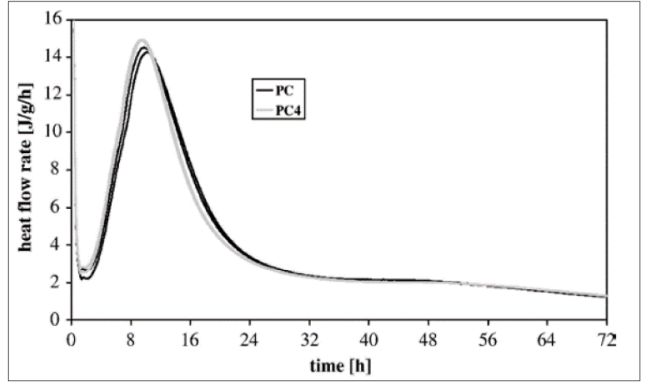

(c)

Fig. 12. Measured heat flow during hydration from the literature using X-ray diffraction ((a) [215] and (b) [214]) and isothermal conduction calorimetry ((c), [3]) with (PC4) and without (PC) limestone.

between the solution and the hydrated fraction of the cement. The accuracy of these simulations appears to justify this approach, showing close agreement with other models. Placing kinetic constraints on the reaction of the initial clinker minerals prevents their immediate and complete reaction with the entire pore solution. In this way, a reasonably robust approach to modelling hydration chemistry is demonstrated using PHREEQC as a chemical simulator of the HYDCEM model. However, it should be highlighted again that the cement dissolution modelled here using the Parrot \& Killoh method, which has a significant influence on the precipitation of solid hydrates does not take account of the effect of limestone on the rate of hydration.

Previous work using PHREEQC to model cement hydration focussed on OPC, GGBS and fly-ash. No previous literature exists, at the time of writing, which demonstrates PHREEQC's capability to model the inclusion of limestone in cementitious binders. This paper demonstrates successfully that this is now possible, notwithstanding the assumptions around the binder dissolution and calcite volume over time mentioned above.

Although the methods described here are complete and reliable, further development is ongoing to integrate hydration simulations into a single input file. Ultimately, this will facilitate the automatic modelling of the uptake of dissolved elements in the pore solution by the solid hydrates to complete the long-term evolution of cement hydration.

\section{Declaration of Competing Interest}

The authors declare that they have no known competing financial interests or personal relationships that could have appeared to influence 


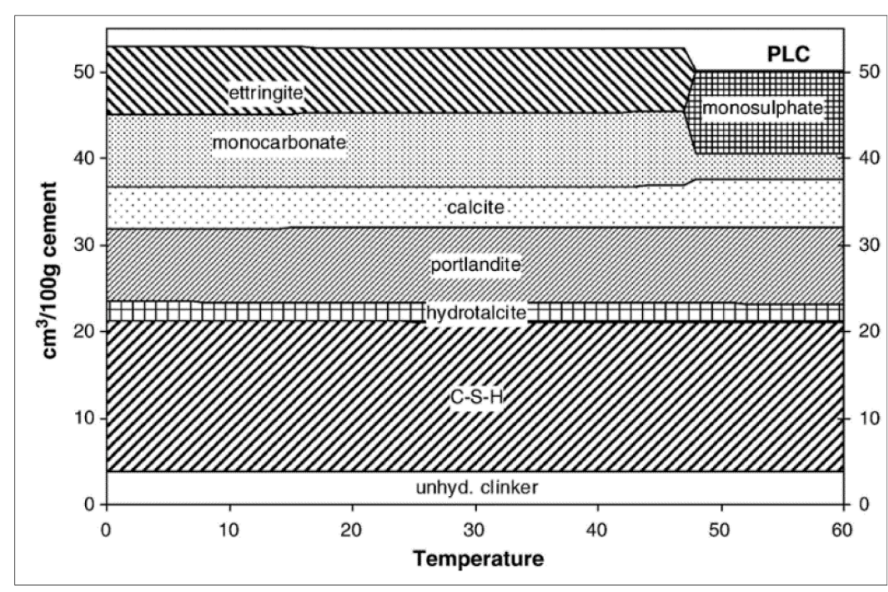

(a)

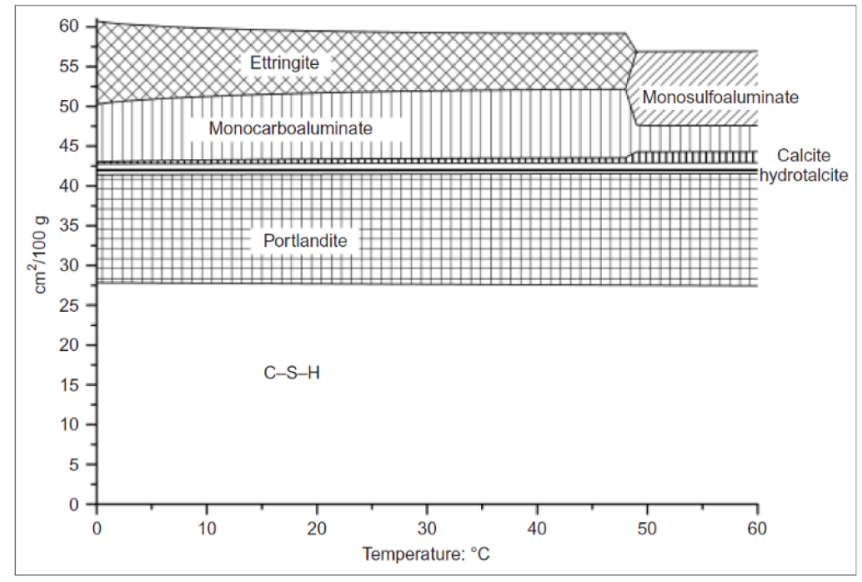

(b)

Fig. 13. Effect of increasing temperature on limestone cements $[106,210]$.

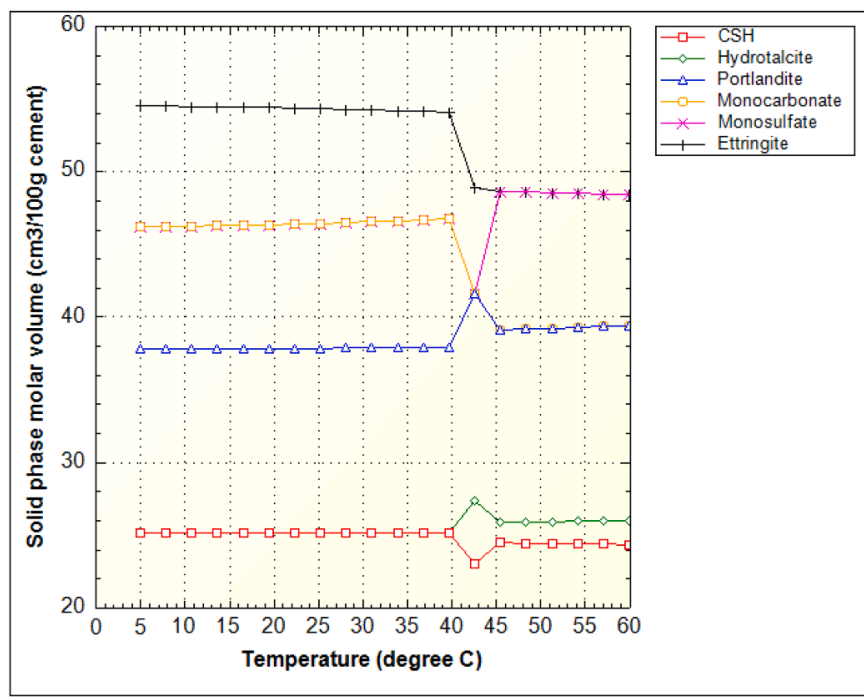

(a)

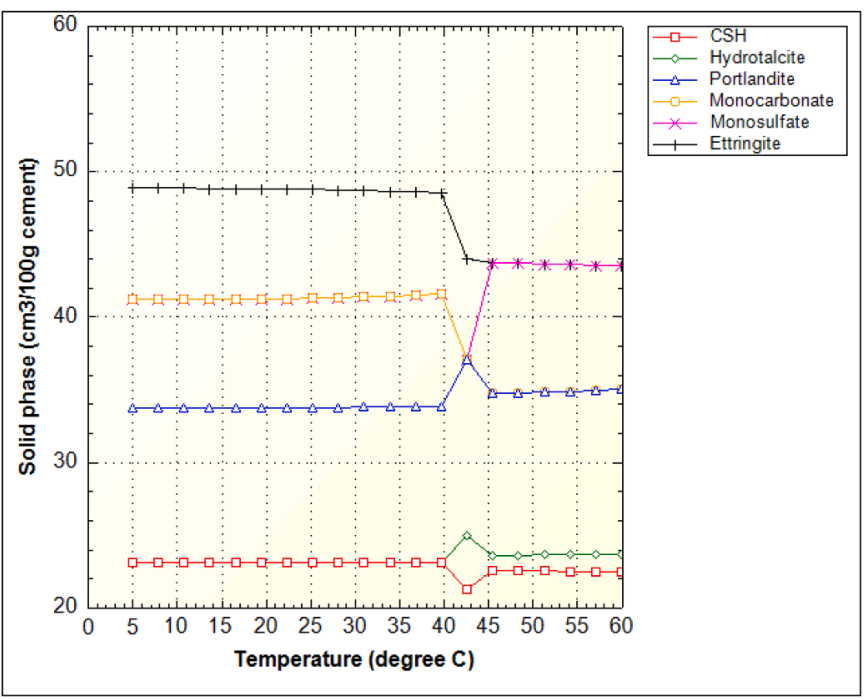

(b)

Fig. 14. Effect of increasing temperature on the stability of solid hydrated phases for the (a) CEM I and (b) CEM II/A-L.

the work reported in this paper.

\section{Acknowledgements}

The authors would like to acknowledge the valuable advise provided by Dr. Colin Walker and Dr. Tony Appelo during the production of this paper.

\section{References}

[1] D. Kulik, GEMS-PSI 2.2007, available at http://gems.web.psi.ch/.

[2] B. Lothenbach, et al., Cemdata18: A chemical thermodynamic database for hydrated Portland cements and alkali-activated materials, Cem. Concr. Res. 115 (2019) 472-506.

[3] B. Lothenbach, et al., Influence of limestone on the hydration of Portland cements, Cem. Concr. Res. 38 (2008) 848-860.

[4] Y. Elakneswaran, et al., Hydration study of slag-blended cement based on thermodynamic considerations, Constr. Build. Mater. 124 (2016) 615-625.

[5] D.L. Parkhust, C.A.J. Appelo. A computer program for speciation, batch - reaction, one - dimensional transport and inverse geochemical calculations. 1999, USGS.

[6] D. Rothstein, et al., Solubility behavior of Ca-, S-, Al-, and Si-bearing solid phases in Portland cement pore solutions as a function of hydration time, Cem. Concr. Res. 32 (2002) 1663-1671.

[7] B. Lothenbach, et al., Effect of temperature on the pore solution, microstructure and hydration products of Portland cement pastes, Cem. Concr. Res. 37 (2007) 483-491.
[8] F. Winnefeld, B. Lothenbach, Thermodynamic modelling of the hydration of Portland Cement, Cem. Concr. Res. 36 (2006) 209-226.

[9] T. Wolery. EQ3/6 A Software Package for Geochemical Modeling. 2010, Lawrence Livermore National Lab ((LLNI): Livermore, CA (United States).

[10] J. Lee, CHESS Tutorial and Cookbook, Ecole Nationale Supérieure des Mines de Paris, Paris, 2002.

[11] British_Standards_Institute, BS EN 197-1 Cement: Composition, specification and conformity criteria for common cements. 2000.

[12] D.P. Bentz, Modeling the influence of limestone filler on cement hydration using CEMHYD3D, Cem. Concr. Compos. 28 (2) (2006) 124-129.

[13] Laboratory, C.a.C.R., Cement and concrete reference laboratory proficiency sample program: final report on Portland cement proficiency samples number 151 and 152. 2004, NIST.

[14] A.R. Mohamed, M. Elsalamawy, M. Ragab, Modeling the influence of limestone addition on cement hydration, Alexandria Eng. J. 54 (1) (2015) 1-5.

[15] J. Pera, S. Husson, B. Guilhot, Influence of finely ground limestone on cement hydration, Cem. Concr. Compos. 21 (2) (1999) 99-105.

[16] N. Holmes, D. Kelliher, M. Tyler, Simulating cement hydration using HYDCEM, Constr. Build. Mater. 239 (2020).

[17] N. Holmes, D. Kelliher, M. Tyrer. Thermodynamic cement hydration modelling using HYDCEM. in Civil Engineering Research in Ireland 2020. 2020. Cork.

[18] D.J. Parkhurst, C.A.J. Appelo, Description of Input and Examples for PHREEQC Version 3 - A Computer Program for Speciation, Batch-reaction, One-dimensional Transport and Inverse Geochemical Calculations, USGS, Denver, 2013.

[19] D. Postma, C.A.J. Appelo, Geochemistry groundwater and pollution. 2009: CRC Press Taylor \& Francis Group.

[20] S.R. Charlton, D.L. Parkhurst, Modules based on the geochemical model PHREEQC for use in scripting and programming languages, Comput. Geosci. 37 (2011) 1653-1663. 
[21] Y. Elakneswaran, T. Ishida, Development and verification of an integrated physicochemical and geochemical modelling framework for performance assessment of cement-based materials, J. Adv. Concr. Technol. 12 (2014) $111-126$.

[22] F. Georget, J.H. Prévost, R.J. Vanderbei, A speciation solver for cement paste modeling and the semismooth Newton method, Cem. Concr. Res. 68 (2015) $139-147$.

[23] B. Guo, et al., A COMSOL-PHREEQC interface for modeling the multi-species transport of saturated cement-based materials, Constr. Build. Mater. 187 (2018) 839-853.

[24] Y. Elakneswaran, T. Ishida, Development and verification of an integrated physicochemical and geochemical modelling framework for performance assessment of cement-based materials, J. Adv. Concr. Technol. 12 (April) (2014) $111-126$.

[25] K. Maekawa, T. Ishida, T. Kishi, Multiscale modeling of structural concrete. 2009: Taylor \& Francis

[26] R.J. Myers, S.A. Bernal, J. Provis, A thermodynamic model for C-(N-)A-S-H gel: CNASH_ss. Derivation and validation, Cem. Concr. Res. 66 (2014) 27-47.

[27] Y. Elakneswaran, E. Owaki, T. Nawa, Modelling long-term durability performance of cementitious materials under sodium sulphate interaction, Appl. Sci. 8 (2597) (2018) 1-16.

[28] Y. Elakneswaran, et al., Durability of slag-blended cement due to U-phase instability in sulphate environment, Mater. Struct. 53 (146) (2020) 1-12.

[29] S. Krishnya, Y. Yoda, Y. Elakneswaran, A two-stage model for the prediction of mechanical properties of cement paste, Cem. Concr. Compos. 115 (2021) 1-15.

[30] Y. Elankneswaran, N. Toyohara, O. Eiji. Prediction of hydration products and por solution chemistry of fly ash cement. in Proceedings of Academicsera International Conference. 2018. Milan.

[31] K.L. Scrivener, R. Snellings, B. Lothenbach, A Practical Guide to Microstructural Analysis of Cementitious Materials. 2017: CRC Press.

[32] B. Lothenbach, Calculation of ternary diagrams by mass balance calculations in MS Excel. 2021, EMPA.

[33] E.G. King, Heats of formation of crystalline calcium orthosilicate, tricalcium silicate and zinc orthosilicate, J. Am. Chem. Soc. 73 (1951) 656-658.

[34] S. Todd, Low temperature heat capacities and entropies at $298.16 \mathrm{ok}$ of crystalline calcium orthosilicate, zinc orthosilicate and tricalcium silicate, J. Am. Chem. Soc. 73 (1951) 3277-3278.

[35] K.K. Kelley, Contributions to the data in theoretical metallurgy XIII: High temperature heat content, heat capacities and entropy data for the elements and inorganic compounds, in United States Bureau of Mines Bulletin, 584. 1960. p. 232.

[36] K.K. Kelley, E.G. King, Contributions to the data on theoretical metlallurgy. XIV. Entropies of the elements and inorganic compounds, in United States Bureau of Mines Bulletin, 592. 1961. p. 149.

[37] J.P. Coughlin, Heats of formation of crystalline cao.Al2o3, 12cao.7al2o3, and 3cao.Al2o3, J. Am. Chem. Soc. 78 (1956) 5479-5482.

[38] V.I. Babushkin, G.M. Matveyev, O.P. Mchedlov-Petrossyan, Thermodynamics of Silicates, Springer-Verlag, Berlin, 1985.

[39] D.R. Stull, H. Prophet. JANAF thermochemical tables. 1971, National Bureau of Standards: Washington, DC, USA.

[40] H.C. Helgeson, et al., Summary and critique of the thermodynamic properties of rock-forming minerals, Am. J. Sci. (1978) 1-229.

[41] P.A.G. O'Hare, Thermochemical and theoretical investigations of the sodiumoxygen system. I The standard enthalpy of formation of sodium oxide (Na2O), J. Chem. Phys. 56 (1972) 4513-4516.

[42] H.C. Helgeson, et al., Summary and critique of the thermodynamic properties of rock-forming minerals, Am. J. Sci. 278a (1978) 1-229.

[43] R.A. Robie, D.R. Waldbaum, Thermodynamic properties of minerals and related substances at $298.15 \mathrm{oK}(25.0 \mathrm{oC})$ and one atmosphere (1.013 bars) pressure and at higher temperatures, in United States Geological Survey Bulletin. p. 1-256.

[44] K.C. Mills, Thermodynamic Data for Inorganic Sulphides, Selenides and Tellurides, Butterworths, London, 1974.

[45] E.J.J. Huber, C.E.J. Holley, The heat of combustion of calcium, J. Phys. Chem. 60 (1956) 498-499.

[46] L.N. Plummer, E. Busenberg, The solubilities of calcite, aragonite and vaterite in $\mathrm{CO} 2-\mathrm{H} 2 \mathrm{O}$ solutions between 0 and $90 \mathrm{oC}$, and an evaluation of the aqueous model for the system CaCO3-CO2-H2O, Geochim. Cosmochim. Acta 46 (1982) 1011-1040.

[47] V.B. Parker, D.D. Wagman, W.H. Evans, Selected values of chemical thermodynamic properties. NBS Technical Note 270-6, p.119, National Bureau of Standards: Washington.

[48] R.A. Robie, S. Russell-Robinson, B.S. Hemingway, Heat capacities and entropies from 8 to $1000 \mathrm{k}$ of langbeinite (k2mg2(so4)3), anhydrite (caso4) and of gypsum (caso4.2h2o) to 325 k, Thermochim Acta 139 (1989) 67-81.

[49] R.A. Robie, B.S. Hemingway, Thermodynamic properties of minerals and related substances at $298.15 \mathrm{~K}$ and 1 bar $\left(10^{\wedge} 5\right.$ pascals) pressure and at higher temperatures, in United States Geological Survey Bulletin 2131. 1995. p. 461.

[50] L. Clarke, E.P. Partridge, Potassium sulfate from syngenite by high temperature extraction with water, J. Ind. Eng. Chem. 26 (1934) 897-903.

[51] A.E. Hill. Ternary systems XIX. Calcium sulfate, potassium sulfate and water. J. Am. Chem. Soc. 561934 1071-1078.

[52] D. Freyer, W. Voigt, The measurement of sulfate mineral solubilities in the Na_K Ca-Cl-SO4-H2O system at temperatures of 100, 150 and 200oC, Geochim. Cosmochim. Acta 68 (2) (2004) 307-318.

[53] W.E. Hatton, et al., The chemical thermodynamic properties of calcium hydroxide, J. Am. Chem. Soc. 81 (1959) 5028-5030.
[54] C.F. Baes, R.E. Mesmer, The Hydrolysis of Cations, John Wiley \& Sons Inc., New York, 1976.

[55] S.A. Greenberg, T.N. Chang, Investigation of the colloidal hydrated calcium silicates II. Solubility relationships in the calcium-silica-water system at $25<$ C, J. Phys. Chem. 69 (1) (1965) 182-188.

[56] K. Fujii, W. Kondo, Heterogeneous equilibrium of calcium silicate hydrate in water at $30^{\circ} \mathrm{C}$, J. Chem. Soc., Dalton Trans. 2 (1981) 645-651.

[57] M. Grutzeck, A. Benesi, B. Fanning, Silicon-29 magic angle spinning nuclear magnetic resonance study of calcium silicate hydrates, J. Am. Ceram. Soc. 72 (4) (1989) 665-668.

[58] A. Atkinson, J.A. Hearne, C.F. Knights, Aqueous chemistry and thermodynamic modelling of CaO-SiO2-H2O gels at 80 oC. 1991, Department of the Environment (UK) HMIP Report, DoE/HMIP/RR/91/O45.

[59] M. Atkins, F.P. Glasser, A. Kindness, Cement hydrate phases: Solubility at 25oC, Cem. Concr. Res. 22 (1992) 241-246.

[60] F.P. Glasser, et al., The Chemistry of Blended Cement and Backfills Intended for Use in Radioactive Waste Disposal, Environment Agency, Bristol, 1999.

[61] A.C. Courault, Simulation experimentale des C-S-H dans les betons modernes: Etude de la composition et des proprietes a l'equilibre dans des milieux complexes. 2000, Laboratoire de Recherches sur la Reactivite des Solides, Ph.D., p. 212. Universite de Bourgogne: Dijon.

[62] I. Pointeau, tude mecanistique et modelisation de la retention de radionucleides par les silicates de calcium hydrates (CSH) des ciments. 2000, Chimie, Ph.D., p. 198 L'Universite de Reims Champage-Ardenne, Reims, France.

[63] R. Barbarulo, Comportement des materiaux cimentaires: Actions des sulfates et de la temperature. 2002, Departement de genie civil, Ph.D., p. 272. Universite Laval: Quebec, Canada.

[64] A.W. Harris, et al., Testing of models of the dissolution of cements - leaching of synthetic CSH gels, Cem. Concr. Res. 32 (5) (2002) 731-746.

[65] J.J. Chen, et al., Solubility and structure of calcium silicate hydrate, Cem. Concr. Res. 34 (9) (2004) 1499-1519.

[66] A.V. Chambers, T.G. Heath, F.M.I. Hunter, M.C. Manning, S.J. Williams. The effect of sodium chloride on the dissolution of calcium silicate hydrate gels. 2005, Serco Assurance: Didcot, UK.

[67] S.W. Swanton, H.J. Fairbrother, N.A. Turner, The effect of sodium chloride on the dissolution of calcium silicate hydrate gels. II. Effect of temperature and cation type. 2005, Serco Assurance Report SA/ENV-0725: UK.

[68] P. Henocq, Modelisation des interactions ioniques a la surface des silicates de calcium hydrates. 2005, Ph.D. L'Universite Laval: Quebec, Canada.

[69] C.S. Walker, et al., Non-ideal solid solution aqueous solution modeling of synthetic calcium silicate hydrate, Cem. Concr. Res. 37 (4) (2007) 502-511.

[70] D. Sugiyama, Chemical alteration of calcium silicate hydrate (C-S-H) in sodium chloride solution, Cem. Concr. Res. 38 (12) (2008) 1270-1275.

[71] M. Atkins, et al. Thermodynamic modelling of blended cements at elevated temperature (50-90oC). 1994, Department of the Environment (UK) HMIP report DoE/HMIP/RR/94.011: London.

[72] G. Plusquellec, Analyse in situ de suspensions de silicate de calcium hydrate: Application aux interactions ioniques a la surface des particules. 2014, Laboratoire Interdisplinaire Carnot de Bourgogne, Ph.D thesis, Universite de Bourgogne: Dijon, France.

[73] E. L'Hopital, Aluminium and alkali uptake in calcium silicate hydrates (C-S-H). 2014, Laboratoire des Materiaux de Construction, Ph.D. thesis, Ecole Polytechnique Federale de Lausanne: Lausanne, Switzerland.

[74] J. Haas, A. Nonat, From C-S-H to C-A-S-H: experimental study and thermodynamic modelling, Cem. Concr. Res. 68 (2) (2015) 124-138.

[75] R.J. Myers, et al., Composition-solubility-structure relationships in calcium (alkali) aluminosilicate hydrate (C-(N, K-)A-S-H), Dalton Trans. 44 (2015) $13530-13544$.

[76] R.J. Myers, et al., Effect of temperature and aluminium on calcium (alumino) silicate hydrate chemistry under equilibrium conditions, Cem. Concr. Res. 68 (2015) 83-93.

[77] C. Roosz, Proprietes thermodynamiques des phases cimentaires hydratees : $\mathrm{C}-\mathrm{S}$ - $\mathrm{H}, \mathrm{C}$ A-S-H etM-S-H. 2015, Institut de Chimie desMilieux et Materiaux de Poitiers, $\mathrm{Ph}$. D. these, Universite de Poitiers: Poitiers, France.

[78] S.W. Swanton, T.G. Heath, A. Clacher, Leaching behavior of low Ca: Si ratio CaOSiO2-H2O systems, Cem. Concr. Res. 88 (2016) 82-95.

[79] C.S. Walker, et al., Calcium silicate hydrate (C-S-H) gel solubility data and a discrete solid phase model at $25 \mathrm{oC}$ based on two binary non-ideal solid solutions, Cem. Concr. Res. 79 (2016) 1-30.

[80] F.E. Jones, The quaternary system CaO-Al2O3-CaSO4-H2O at 25oC, Trans. Faraday Soc. 35 (1939) 1484-1510.

[81] J. Ederova, V. Satava, Heat capacities of C3AH6, C4A\$H12 and C6A\$332, Thermochim. Acta 31 (1979) 126-128.

[82] M. Atkins, et al., Solubility properties of ternary and quaternary compounds in the CaO_Al2O3-SO3-H2O system, Cem. Concr. Res. 21 (1991) 991-998.

[83] D. Damidot, et al., Sulfphate attack on concrete: limits of the AFt stability domain, Cem. Concr. Res. 22 (2-3) (1992) 229-234.

[84] C.J. Warren, E.J. Reardon, The solubility of ettringite at $25^{\circ} \mathrm{C}$, Cem. Concr. Res. 24 (1994) 1515-1524.

[85] R.B. Perkins, C.D. Palmer, Solubility of ettringite (Ca6[Al(OH)6]2(SO4) 3\#26H2O) at 5-75 C, Geochim. Cosmochim. Acta 13 (14) (1999) 1969-1980.

[86] I. Baur, et al., Dissolution-precipitation behaviour of ettringite, monosulfate, and calcium silicate hydrate, Cem. Concr. Res. 34 (2004) 341-348.

[87] D.E. Macphee, S.J. Barnett, Solution properties of solids in the ettringitethaumasite solid solution series, Cem. Concr. Res. 34 (2004) 1591-1598. 
[88] G. Möschner, et al., Solubility of Fe-ettringite (Ca6[Fe(OH)6]2(SO4)3.26H2O), Geochim. Cosmochim. Acta 72 (2008) 1-18.

[89] M.Y. Hobbs, Solubilities and ion exchange properties of solid solutions between the $\mathrm{OH}, \mathrm{Cl}$ and $\mathrm{CO} 3$ end members of the monocalcium aluminate hydrates. 2001, Ph.D. Thesis University of Waterloo: Ontario.

[90] T. Matschei, B. Lothenbach, F.P. Glasser, Thermodynamic properties of Portland cement hydrates in the system CaO_Al2O3-SiO2_CaSO4_CaCO3-H2O, Cem. Concr. Res. 37 (2007) 1379-1410.

[91] F. Bellmann, et al., Analysis of thermodynamic data of calcium aluminate monocarbonate, Cem. Concr. Res. 116 (2019) 89-94.

[92] B.Z. Dilnesa, et al., Iron in carbonate containing AFm phases, Cem. Concr. Res. 41 (2011) 311-323.

[93] L.S. Wells, W.F. Clarke, H.F. McMurdie, Study of the system CaO_Al2O3-H2O at temperatures of $21^{\circ} \mathrm{C}$ and $90^{\circ} \mathrm{C}$, J. Res. Nat. Bur. Stand. 30 (1943) 367-409.

[94] J.D. D'Ans, H. Eick, Das system CaO_Al2O3-H2O bei 20oC und das erhärten der tonerdezemente, Zem. Kalk Gips 6 (1953) 197-210.

[95] R.B. Peppler, L.S. Wells, The system of lime, alumina and water from $50^{\circ} \mathrm{C}$ to $250^{\circ}$ C, J. Res. Nat. Bur. Stand. 52 (1954) 75-94.

[96] E.T. Carlson, The system lime_Alumina-water at $1^{\circ} \mathrm{C}$, J. Res. Nat. Bur. Stand. 61 (1958) 1-11.

[97] E.T. Carlson, H.A. Berman, Some observations on the calcium aluminate carbonate hydrates. J. Res. Natl. Bureau of Standards, 333-341 64.

[98] F. Zhang, Z. Zhou, Z. Lou, Solubility product and stability of ettringite. in Proceedings of the 7th International Symposium on the Chemistry of Cement, Session II, 1980.

[99] D. Damidot, et al., Thermodynamic investigation of the CaO_Al2O3 CaCO3-H2O closed system at 25oC and the influence of Na2O, Cem. Concr. Res. 24 (3) (1994) 563-572.

[100] P.C. Ho, D.A. Palmer, Determination of ion association in dilute lithium chloride and lithium hydroxide solutions to $6000 \mathrm{C}$ and $300 \mathrm{MPa}$ by electrical measurements, J. Chem. Eng. Data 43 (1998) 162-170.

[101] M. Zhang, Incorporation of oxyanionic b, cr, mo, and se into hydrocalumite and ettringite: Application to cementitious systems. 2000, Ph.D. University of Waterloo: Ontario.

[102] M. Balonis, et al., Impact of chloride on the mineralogy of hydrated Portland cement systems, Cem. Concr. Res. 40 (2010) 1009-1022.

[103] L. Aimoz, et al., Thermodynamics of AFm-(I2, SO4) solid solution and of its endmembers in aqueous media, Appl. Geochem. 27 (2012) 2117-2129.

[104] S.M. Leisinger, et al., Thermodynamic modeling of solid solutions between monosulfate and monochromate 3CaO.Al2O3. $\mathrm{Ca}[(\mathrm{CrO} 4) \mathrm{x}(\mathrm{SO} 4) 1-\mathrm{x}] . \mathrm{nH} 2 \mathrm{O}$, Cem. Concr. Res. 42 (2012) 158-165.

[105] L.G. Baquerizo, et al., Hydration states of AFm cement phases, Cem. Concr. Res. 73 (2015) 143-157.

[106] B. Lothenbach, et al., Thermodynamic modelling of the effect of temperature on the hydration and porosity of Portland cement, Cem. Concr. Res. 38 (2008) 1-18.

[107] B.Z. Dilnesa, et al., Stability of monosulfate in the presence of iron, J. Am. Ceram. Soc. 95 (10) (2012) 3305-3316.

[108] D.G. Bennett, et al., A thermodynamic model for blended cements. II: cement hydrate phases; thermodynamic values and modelling studies, J. Nucl. Mater. 190 (1992) 315-325.

[109] T.G. Jappy, F.P. Glasser, Synthesis and stability of silica-substitued hydrogarnet Ca3Al2Si3-XO12-4X(OH)4X, Adv. Cem. Res. 4 (1) ('1992.) 1-8.

[110] K.C. Quillin, A.J. Majumdar, Phase equilibra in the CaO_Al2O3-SiO2-H2O system at $5^{\circ} \mathrm{C}, 20^{\circ} \mathrm{C}$ and $30^{\circ} \mathrm{C}$, Adv. Cem. Res. 6 (22) (1994) 47-56.

[111] B.Z. Dilnesa, et al., Synthesis and characterization of hydrogarnet Ca3(AlxFe1-x)2 (SiO4)y(OH)4(3-y), Cem. Concr. Res. 59 (2014) 96-111.

[112] R.K. Allada, A. Navrotsky, J. Boerio-Goates, Thermochemistry of hydrotalcite-like phases in the $\mathrm{MgO}$ _Al2O3-CO2-H2O system: a determination of enthalpy, entropy and free energy, Am. Mineral. 90 (2005) 329-335.

[113] A.T. Nouvel, Sur la solubilite de $\mathrm{Mg}(\mathrm{OH}) 2$ aux temperatures elevees, Comptes Rendus Hebdomadaires des Seances de l'Academie 188 (1929) 499-501.

[114] E.G. King, M.J. Ferrante, L.B. Pankratz, Thermodynamic data for $\mathrm{Mg}(\mathrm{OH}) 2$ (brucite). 1975, United States Bureau of Mines Report of Investigations.

[115] K.A. McGee, P.B. Hostetler, Activity-product constants of brucite from $10^{\circ}$ to $90^{\circ} \mathrm{C}$, US Geol. Surv, J. Res, 5 (2) (1977) 227-233.

[116] P.L. Brown, S.E.J. Drummond, D.A. Palmer, Hydrolysis of magnesium (II) at elevated temperatures, J. Chem. Soc., Dalton Trans. (1996) 3071-3075.

[117] Y. Xiong, Thermodynamic properties of brucite determined by solubility studies and their significance to nuclear waste isolation, Aquat. Geochem. 14 (2008) 223-228.

[118] R.J. Lemire, et al., Chemical thermodynamics of iron, part 1. OECD Nuclear Enegy Agency, Issy-les-Moulineaux, France, 2013.

[119] V.A. Pokrovskii, H.C. Helgeson, Thermodynamic properties of aqueous species and the solubilities of minerals at high pressures and temperatures: the system Al2O3-H2O-NaCl, Am. J. Sci. 295 (1995) 1255-1342.

[120] D.A. Palmer, D.J. Wesolowski, Potentiometric measurements of the first hydrolysis quotient of magnesium(II) to $250^{\circ} \mathrm{C}$ and 5 molal ionic strength ( $\mathrm{NaCl}$ ), J. Solution Chem. 26 (1997) 217-232.

[121] V.C. Farmer, D.G. Lumsdon, An assessment of complex formation between aluminium and silicic acid in acid solutions, Geochim. Cosmochim. Acta 58 (16) (1994) 3331-3334.

[122] G.S. Pokrovski, et al., The stability of aluminium silicate complexes in acidic solutions from 25 to 150oC, Geochim. Cosmochim. Acta 60 (14) (1996) 2495-2501.

[123] S. Salvi, G.S. Pokrovski, J. Schott, Experimental investigation of aluminum-silica aqueous complexing at $300^{\circ} \mathrm{C}$, Chem. Geol. 151 (1-4) (1998) 51-67.
[124] L. Spadini, P.W. Schindler, S. Sjöberg, On the stability of the AlOSi(OH)32+ complex in aqueous solution, Aquat. Geochem. 11 (1) (2005) 21-31.

[125] J.D. Cox, CODATA recommended key values for thermodynamics, 1977 report of the codata task group on key values for thermodynamics, 1977, J. Chem. Thermodyn. 10 (1978) 903-906.

[126] E.L. Shock, H.C. Helgeson, Calculation of the thermodynamic and transport properties of aqueous species at high pressures and temperatures: Correlation algorithms for ionic species and equation of state predictions to $5 \mathrm{~kb}$ and 1000degC, Geochim. Cosmochim. Acta 52 (1988) 2009-2036.

[127] C.S. Walker, et al. Formation of metal ion complexes in cementitious porewater and leachates. in 15th International Congress on the Chemistry of Cement. 2019. Prague, Czech Republic.

[128] D.A. Sverjensky, E.L. Shock, H.C. Helgeson, Prediction of the thermodynamic properties of aqueous metal complexes to $1000 \mathrm{C}$ and $5 \mathrm{~kb}$, Geochim. Cosmochim. Acta 61 (1997) 1359-1412.

[129] I. Greenwald, The dissociation of calcium and magnesium carbonates and bicarbonates, J. Biol. Chem. 141 (1941) 789-796.

[130] R.M. Garrels, M.E. Thompson, A chemical model for seawater at $250 \mathrm{C}$ and one atmosphere total pressure, Am. J. Sci. 260 (1) (1962) 402-418.

[131] F.S. Nakayama, Calcium activity, complex and ion-pair formation in saturated CaCO3 solutions, Soil Sci. 106 (6) (1968) 429-434.

[132] R.L. Jacobson, D. Langmuir, Dissocation constants of calcite and CaHCO3+ from 0 to 50oC, Geochim. Cosmochim. Acta 38 (1974) 301-318.

[133] E.J. Reardon, D. Langmuir, Thermodynamic properties of the ion pairs MgCO3 and CaCO3 from 10 to 50oC, Am. J. Sci. 274 (1974) 599-612.

[134] T.E. Larson, F.W.J. Sollo, F.F. McGurk, Complexes affecting the solubility of calcium carbonate in water - phase II. Water Resources Center Report 108. 1976, University of Illinois: Urbana-Champaign, Urbana, IL, USA.

[135] G. Dorange, A. Marchand, A. Franco, Solubilité de la cérusite et constantes de stabilité de $\mathrm{PbOH}+, \mathrm{PbCO} 30$ et $\mathrm{PbHCO}+$, Tribune de l'eau 42 (1989) 53-59.

[136] R.M. Smith, A.E. Martell, Critical stability constants Volume 4: Inorganic Complexes. 1976, New York, NY, USA: Springer Science + Business Media.

[137] E.L. Shock, et al., Inorganic species in geological fluids: correlations among standard molal thermodynamic properties of aqueous ions and hydroxide complexes, Geochim. Cosmochim. Acta 61 (1997) 907-950.

[138] P.H. Santschi, P.W. Schindler, Complex formation in the ternary systems CaIIH4SiO4-H2O and MgII-H4SiO4-H2O, J. Chem. Soc. (1974) 181-184.

[139] D.R. Turner, M. Whitfield, A.G. Dickson, The equilibrium speciation of dissolved components in freshwater and seawater at $25^{\circ} \mathrm{C}$ and $1 \mathrm{~atm}$ pressure, Geochim. Cosmochim. Acta 45 (1981) 855-881.

[140] L.B. Yeatts, W.L. Marshall, Apparent invariance of activity coefficients of calcium sulfate at constant ionic strength and temperature in the system CaSO4_Na2SO4 NaNO3-H2O to the critical temperature of water, J. Phys. Chem. 73 (1969) 83-90.

[141] D.D. Wagman, et al., The NBS tables of chemical thermodynamic properties, selected values for inorganic and $\mathrm{c} 1$ and $\mathrm{c} 2$ organic substances in SI units, J. Phys. Chem. Ref. Data 11 (1982) 392.

[142] R.L. Berg, C.E. Vanderzee, Thermodynamics of carbon dioxide and carbonic acid: (a) the standard enthalpies of $\mathrm{Na} 2 \mathrm{CO} 3(\mathrm{~s}), \mathrm{NaHCO} 3(\mathrm{~s})$ and $\mathrm{CO} 2(\mathrm{~g})$ in water at $298.15 \mathrm{~K}$; (b) the standard enthalpies of formation, standard gibbs energies of formation, and standard entropies of $\mathrm{CO} 2(\mathrm{aq}), \mathrm{HCO}, \mathrm{J}$. Chem. Thermodyn. 10 (1978) 1113-1136.

[143] X. Liu, F.J. Millero, The solubility of iron hydroxide in sodium chloride solutions, Geochim. Cosmochim. Acta 63 (1999) 3487-3497.

[144] A. Stefansson, Iron (III) hydrolysis and solubility at 25oC, Environ. Sci. Technol. 41 (17) (2007) 6117-6123.

[145] A.A. Kamnev, et al., Investigation of the solution process of goethite (alpha$\mathrm{FeOOH}$ ) in alkaline solutions, Russian J. Appl. Chem. (Zhurnal Prikladnoi Khimii) 59 (1986) 1560-1564.

[146] Z. Yishin, A. Ruiyang, Y. Chen, Determination of the solubility of Fe2O3 in dilute aqueous solutions at 300oC and $10 \mathrm{MPa}$, Scientia Sinica Series B 29 (1986) $1221-1232$.

[147] S.E. Ziemniak, M.E. Jones, K.E.S. Combs, Magnetite solubility and phase stability in alkaline media at elevated temperatures, J. Solution Chem. 24 (1995) 837-877.

[148] K. Kuma, J. Nishioka, K. Matsunaga, Controls on iron(III) hydroxide solubility in seawater: The influence of $\mathrm{pH}$ and natural organic chelators, Limnol. Oceanogr. 41 (3) (1996) 396-407.

[149] I.I. Diakonov, et al., Iron(III) solubility and speciation in aqueous solutions. Experimental study of the modelling: Part 1. Hematite solubility from 60 to $00 \mathrm{oC}$ in $\mathrm{NaOH}-\mathrm{NaCl}$ solutions and thermodynamic properties of $\mathrm{Fe}(\mathrm{OH}) 4-(\mathrm{aq})$, Geochim. Cosmochim. Acta 63 (15) (1999) 2247-2261.

[150] E.I. Sergeeva, O.M. Suleimenov, A.V. Evstigneev, Solubility of hematite, Fe2O3 (cr, a) at $200^{\circ} \mathrm{C}$ and the standard entropy of $\mathrm{Fe} 3+$ ion in aqueous solution, Geochem. Int. 37 (1999) 1097-1107.

[151] W.N. Perera, G. Hefter, Mononuclear cyano- and hydroxo- complexes of iron(III), Inorg. Chem. 42 (2003) 5917-5923.

[152] D.O. Whittemore, D. Langmuir, Standard electrode potential of Fe3 $++\mathrm{e}-=\mathrm{Fe} 2+$ from 5-35 C, J. Chem. Eng. Data 17 (1972) 288-290.

[153] E.L. Shock, H.C. Helgeson, D.A. Sverjensky, Calculation of the thermodynamic and transport properties of aqueous species at high pressures and temperatures: Standard partial molal properties of inorganic neutral species, Geochim. Cosmochim. Acta 53 (1989) 2157-2183.

[154] M. Uematsu, E.U. Franck, Static dielectric constant of water and steam, J. Phys. Chem. Ref. Data 9 (1980) 1291-1304.

[155] J.M.H. Levelt-Sengers, et al., Thermodynamic properties of steam in the critical region, J. Phys. Chem. Ref. Data 12 (1983) 1-28. 
[156] K.S. Pitzer. Dielectric constant of water at very high temperature and pressure. in Proceedings of the National Academy of Sciences. 1983. USA.

[157] I. Haar, J.S. Gallagher, G.S. Kell. NBS/NRC steam tables. Thermodynamic and transport properties and computer programs for vapor and liquid states of water in SI units. 1984, Hemisphere Publishing Corporation: Washington, DC, USA.

[158] H.C. Helgeson, D.H. Kirkham, Theoretical predictions of the thermodynamic properties of aqueous electrolytes at high pressures and temperatures. II. DebyeHuckel parameters for activity coefficients and relative partial molal properties, Am. J. Sci. 274 (1974) 1199-1261.

[159] V.A. Pokrovskii, H.C. Helgeson, Thermodynamic properties of aqueous species and the solubilities of minerals at high pressures and temperatures: the system Al2O3-H2O KOH, Chem. Geol. 137 (1997) 221-242.

[160] H.C. Helgeson, D.H. Kirkham, Theoretical prediction of the thermodynamic behavior of aqueous electrolytes at high pressures and temperatures: III. Equation of state for aqueous species at infinite dilution, Am. J. Sci. 276 (1976) 97-240.

[161] R.P. Bell, J.H.B. George, Incomplete dissocation of some thallous and calcium salts at different temperatures, Trans. Faraday Soc. 49 (1953) 619-627.

[162] A.S.Q.E.U. Franck, H.R. Jolley, W.L. Marshall, Electrical conductances of aqueous solutions at high temperature and pressure. I. The conductances of potassium sulfate-water solutions from 25 to $800 \mathrm{oC}$ and at pressures up to 4000 bars, J. Phys. Chem. 67 (1963) 2453-2459.

[163] A.H. Truesdell, P.B. Hopstetler, Dissociation constants of KSO4- from $10^{\circ}-50^{\circ} \mathrm{C}$, Geochim. Cosmochim. Acta 32 (1968) 1019-1022.

[164] P. Shin, C.M. Criss, Standard enthalpies of formation of anhydrous and aqueous magnesium chloride at $298.15 \mathrm{~K}, \mathrm{~J}$. Chem. Thermodyn. 11 (1979) 636-666.

[165] R.M. Siebert, P.B. Hostetler, The stability of the magnesium carbonate ion pair from $10^{\circ}$ to $90^{\circ} \mathrm{C}$, Am. J. Sci. 277 (1977) 716-734.

[166] D.A. Sverjensky, Thermodynamic properties of aqueous inorganic metal complexes. Geochimica et Cosmochimica Acta, 1990: p. cited as being in preparation.

[167] I.M. Kolthoff, Die dissoziationskonstante der erdalkalihydroxyde, Recl. Trav. Chim. Pays-Bas 42 (1923) 973-979.

[168] J.K. Gjaldbaek, Untersuchungen über die löslichkeit des magnesiumhydroxyds. II Löslichkeitsprodukte und die dissoziationkonstante der magnesiumhydroxyde, Zeitschrift für Anorganische und Allgemeine Chemie 144 (1925) 269-288.

[169] J.V. Walther, Experimental determination of portlandite solubility and brucite solubilities in supercritical H2O, Geochim. Cosmochim. Acta 50 (1986) 733-739.

[170] P.L. Brown, C. Ekberg, Hydrolysis of metal ions (Vol. 2). 2016, Weinheim, Germany: Wiley-VCH.

[171] T.M. McCollom, E.L. Shock, Geochemical constraints on chemolithoautotrophic metabolism by microorganisms in seafloor hydrothermal systems, Geochim. Cosmochim. Acta 61 (20) (1997) 4375-4391.

[172] J.N. Butler, R. Huston, Activity coefficients and ion pairs in the systems sodium chloride - sodium bicarbonate - water and sodium chloride - sodium carbonate water, J. Phys. Chem. 74 (1970) 2976-2983.

[173] S.G. Capewell, G. Hefter, P.M. May, Potentiometric investigation of the weak association of sodium and carbonate ions at 25oC, J. Solution Chem. 27 (1998) 868-877.

[174] F. Crea, et al., Protonation of carbonate in aqueous tetraalkylammonium salts at $25^{\circ} \mathrm{C}$, Talanta 68 (2006) 1102-1112.

[175] A. Stefansson, P. Benezeth, J. Schott, Carbonic acid ionization and the stability of sodium bicarbonate and carbonate ion pairs to $200^{\circ} \mathrm{C}$ - a potentiometric andspectrophotometric study, Geochim. Cosmochim. Acta 320 (2013) 600-611.

[176] F.S. Nakayama, Thermodynamic functions for the dissociation of $\mathrm{NaHCO}^{\wedge} 0$, NaCO3-, H2CO3 and HCO3-, J. Inorg. Nucl. Chem. 33 (1971) 1287-1291.

[177] T.M. Seward, Determination of the first ionization constant of silicic acid from quartz solubility in borate buffer solutions to $350^{\circ} \mathrm{C}$, Geochim. Cosmochim. Acta 38 (11) (1974) 1651-1664.

[178] G.S. Pokrovski, J. Schott, A.S. Sergeyev, Experimental determination of the stability constants of NaSO4- and $\mathrm{NaB}(\mathrm{OH}) 4$ in hydrothermal solutions using a new high-temperature sodium-selective glass electrode - implications for boron isotopic fractionation, Chem. Geol. 124 (1995) 253-265.

[179] G. Olofsson, et al., Calorimetric measurements on slightly soluble gases in water. Enthalpies of solution of helium, argon, krypton, xenon, methane, ethane, propane, 1-butane, and oxygen at 288.15, 298.15 and 308.15 K, J. Chem. Thermodyn. 16 (1984) 1041-1052.

[180] G.C. Kennedy, A portion of the system silica-water, Econ. Geol. 45 (1950) 629-653.

[181] G.W. Morey, J.M. Hesselgesser, The solubility of quartz and some other substances in superheated steam at high pressures, Am. Soc. Mech. Eng. Trans. 73 (1951) 868-875.

[182] R.O. Fournier, Solubility of quartz in the temperature interval from $25^{\circ} \mathrm{C}$ to $300^{\circ} \mathrm{C}$, Geol. Soc. Am. Bull. 71 (1960) 1867-1868.

[183] S. Kitahara, The solubility of quartz in water at high temperatures and high pressures, Rev. Phys. Chem. Jpn. 30 (2) (1960) 109-114.

[184] J.A.V. Lier, P.L.d. Bruyn, J.T.G. Overbeek, The solubility of quartz. Journal of Physical Chemistry, 641960 1675-1682.

[185] G.W. Morey, R.O. Fournier, J.J. Rowe, The solubility of quartz in water in the temperature interval from $25^{\circ}$ to $300^{\circ} \mathrm{C}$, Geochim. Cosmochim. Acta 26 (1962) 1029-1043.

[186] R. Siever, Silica solubility, $0^{\circ}-200^{\circ} \mathrm{C}$, and the diagenesis of siliceous sediments, J. Geol. 70 (1962) 127-150.

[187] D.F. Weill, W.S. Fyfe, The solubility of quartz in h2o in the range 1000-4000 bars and $400-500^{\circ} \mathrm{c}$, Geochim. Cosmochim. Acta 28 (1964) 1243-1255.
[188] G.M. Anderson, C.W. Burnham, The solubility of quartz in supercritical steam, Am. J. Sci. 263 (1965) 494-511.

[189] D.A. Crerar, G.M. Anderson, Solubility and solvation reactions of quartz in dilute hydrothermal solutions, Chem. Geol. 8 (1971) 107-122.

[190] F.T. Mackenzie, R. Gees, Quartz: synthesis at earth surface conditions, Science 173 (1971) 533-535.

[191] J.J. Hemley, et al., Equilibria in the system al2o3-sio2-h2o and some general implications for alteration/mineralization processes, Econ. Geol. 75 (1980) 210-228.

[192] J.V. Walther, P.M. Orville, The extraction-quench technique for determination of the thermodynamic properties of solute complexes: application to quartz solubility in fluid mixtures, Am. Mineral. 68 (1983) 731-741.

[193] Z. Xie, J.V. Walther, Quartz solubilities in NaCl solutions with and without wollastonite at elevated temperatures and pressures, Geochim. Cosmochim. Acta 57 (1993) 1947-1955.

[194] C.E. Manning, The solubility of quartz in $\mathrm{H} 2 \mathrm{O}$ in the lower crust and uppermantle, Geochim. Cosmochim. Acta 58 (1994) 4831-4839.

[195] J.D. Rimstidt, Quartz solubility at low temperatures, Geochim. Cosmochim. Acta 61 (1997) 2553-2558.

[196] R.C. Newton, C.E. Manning, Quartz solubility in $\mathrm{H} 2 \mathrm{O}-\mathrm{NaCl}$ and $\mathrm{H} 2 \mathrm{O}-\mathrm{CO} 2$ solutions at deep crust-upper mantle pressures and temperatures: 2-15 kbar and 500-900oC, Geochim. Cosmochim. Acta 64 (17) (2000) 2993-3005.

[197] M.C. Davis, et al., Solubility and near-equilibrium dissolution rates of quartz in dilute $\mathrm{NaCl}$ solutions at 398-473 K under alkaline conditions, Geochim. Cosmochim. Acta 75 (2011) 401-415.

[198] E.P. Flint, L.S. Wells, Study of the system CaO-SiO2-H2O at $300 \mathrm{C}$ and of the reaction of water on anhydrous calcium silicates, J. Res. Nat. Bur. Stand. 12 (1934) 751-783.

[199] P.S. Roller, G.J. Ervin, The system calcium-silica-water at 30^o. The association of silicate ion in dilute alkaline solution, J. Am. Chem. Soc. 62 (1940) 461-471.

[200] S.A. Greenberg, E.W. Price, The solubility of silica in solution of electrolytes, J. Phys. Chem. 61 (1957) 1539-1541.

[201] S.A. Greenberg, The nature of the silicate species in sodium silicate solutions, J. Am. Chem. Soc. 80 (1958) 6508-6511.

[202] R. Schwarz, W.D. Muller, Zur kenntnis der kieselsauren. XIV. Die wasserlosliche monokieselsaure, Z. Anorg. Allg. Chem. 296 (1958) 273-279.

[203] N. Ingri, Equilibrium studies of polyanions IV. Silicate ions in $\mathrm{NaCl}$ medium, Acta Chem. Scand. 13 (1959) 758-775.

[204] G. Lagerstrom, Equilibrium studies of polyanions III. Silicate ions in $\mathrm{NaClO} 4$ medium, Acta Chem. Scand. 13 (1959) 722-736.

[205] J. Aveston, Hydrolysis of sodium silicate: ultracentrifugation in chloride solutions, J. Chem. Soc. 821 (1965) 4444-4448.

[206] H. Bilinkski, N. Ingri, A determination of the formation constant of $\mathrm{SiO}(\mathrm{OH}) 3-$, Acta Chem. Scand. 21 (1967) 2503-2510.

[207] R.H. Busey, R.E. Mesmer, Ionization equilibria of silicic acid and polysilicate formation in aqueous sodium chloride solutions to $300^{\circ} \mathrm{C}$, Inorg. Chem. 16 (1977) 2444-2450.

[208] S. Sjoberg, A. Nordin, N. Ingri, Equilibrium and structural studies of silicon(IV) and aluminium(III) in aqueous solution ii. Formation constants for the monosilicate ions $\mathrm{SiO}(\mathrm{OH}) 3-$ and $\mathrm{SiO} 2(\mathrm{OH}) 2^{\wedge} 2$-. A precision study at $25 \mathrm{oC}$ in a simplified seawater medium, Mar. Chem. 10 (1981) 521-532.

[209] S. Sjoberg, et al., Equilibrium and structural studies of silicon(iv) and aluminium (iii) in aqueous solution. V. Acidity constants of silicic acid and the ionic product of water in the medium range 0.05-2.0 M Na(Cl) at 25oC, Mar. Chem. 13 (1983) 35-44.

[210] B. Lothenbach, et al., Thermodynamic modelling: state of knowledge and challenges, Adv. Cem. Res. 22 (4) (2010) 211-223.

[211] L.J. Killoh, D.C. Parrot, Prediction of cement hydration, Br. Ceram. Proc 35 (1984) 41-53.

[212] Y. Elakneswaran, T. Nawa, O.E, Prediction of hydration products and pore solution chemistry of fly ash cement, in Proceedings of Academicsera International Conference. 2018: Milan Italy. p. 10-14.

[213] E. Ogoro, et al. Predicting mortar compressive strength using HYDCEM. in Civil Engineering Research in Ireland (CERI) conference. 2020. Cork.

[214] D. Jensen, et al., Change in reaction kinetics of a Portland cement caused by a superplasticiser - Calculation of heat flow curves from XRD data, Cem. Concr. Res. 42 (2012) 327-332.

[215] D. Jensen, et al., The early hydration of Ordinary Portland Cement (OPC): an approach comparing measured heat flow with calculated heat flow from QXRD, Cem. Concr. Res. 42 (2012) 134-138.

[216] C. Hesse, F. Goetz-Neunhoeffer, J. Neubauer, A new approach in quantitative insitu XRD of cement pastes: correlation of heat flow curves with early hydration reactions, Cem. Concr. Res. 41 (2011) 123-128.

[217] N. Holmes, D. Kelliher, M. Tyrer. HYDCEM: A new cement hydration model. 2019. Eindhoven: ICSBM 2019 2nd International Conference of Sustainable Building Materials.

[218] N. Holmes, D. Kelliher, M. Tyrer. Modelling the addition of limestone in cement using HYDCEM. 2019. Bath: 39th Cement and Concrete Science Conference.

[219] T.C. Powers, B.T. L, Studies of the Physical Properties of Hardened Portland Cement Paste ACI Journal, Proceedings, 1948. 43.

[220] B.S. Institute, Methods of testing cement. Determination of strength, in BS EN 196-1. 2016. 